\title{
V. Die Blockade des deutschen Revisionskurses durch die Militärregierung in Tübingen
}

\section{Die Kontroverse zwischen Landesregierung und Militärregierung um die Interpretation des neuen Spruchkammergesetzes}

Nach dem Oktroi des zoneneinheitlichen Spruchkammergesetzes, mit dem sich die Länder der französischen Zone erst nach Einfügung der Präambel und den Zusagen der Militärregierung abgefunden hatten, ging die Regierung in Württemberg-Hohenzollern davon aus, daß einer allgemeinen Revision der Säuberungsentscheidungen aus der Ära Künzel nun nichts mehr im Wege stehe. Die Regierung hielt es für günstig, einen Mann mit dem Amt des Staatskommissars zu betrauen, der der beabsichtigten Generalrevision aufgeschlossen gegenüberstand und dessen Eigenwilligkeit sich in Grenzen hielt. Denn obgleich der Säuberungskommissar in dem neuen System der Entnazifizierung durch quasi-richterliche Gremien weniger Befugnisse hatte als im Verwaltungsverfahren, kam dem Staatskommissar für die politische Säuberung in der Revisionsfrage - und das war in Württemberg-Hohenzollern jetzt die zentrale Frage die Schlüsselrolle zu. In Anton Traber aus Hechingen ${ }^{1}$, einem Beamten des gehobenen Justizdienstes, der von den Franzosen gleich nach dem Einmarsch mit der kommissarischen Leitung des dortigen Landgerichts beauftragt worden war, glaubte man den geeigneten Kandidaten für diese Aufgabe gefunden zu haben². Das CDU-Mitglied Traber war von Gebhard Müller ins Gespräch gebracht worden, nachdem die Militärregierung eine Reihe profilierter Bewerber aus dem höheren Justizdienst abgelehnt hatte $^{3}$. Die persönliche Integrität des neuen Staatskommissars war bekannt, seine Distanz zum Nationalsozialismus wurzelte in seiner tiefen Religiosität; wegen seiner Lebensführung und Kirchentreue nannte man den streng katholischen Traber in Hechingen bisweilen scherzhaft den „Heiligen Antonius“. In einem privaten Schreiben an seinen Förderer Gebhard Müller bekannte er, neben dem „Gefühl der Anhänglichkeit an Sie, sehr geehrter Herr Ministerialdirektor", habe er sein Amt ,ausschließlich aus Liebe zur Gerechtigkeit und Menschlichkeit" übernommen". Und an Carlo Schmid schrieb er, es sei seine Überzeugung, „daß niemand allein wegen seines politischen Bekenntnisses, seines Beitritts zu einer erlaubten politischen Partei und seine Betätigung in ihr - soweit diese Betätigung im Einzelfalle nicht gegen die guten Sitten oder materielles Strafrecht verstößt - zur Verantwortung gezogen und strafrechtlich

1 Geb. am 23.11. 1897 in Stuttgart.

2 Am 10.6. 1947 von Gebhard Müller in einer Kabinettssitzung erstmals vorgeschlagen, wurde Traber in der DirS am 24.6.1947 zum Staatskommissar für die politische Säuberung berufen.

3 Inf. Gebhard Müller.

${ }^{4}$ Privater Brief Trabers an Gebhard Müller v. 25.6.1947; in seinem Antwortschreiben v. 2. 7. 1947 erinnert Gebhard Müller an die ,lange Zusammenarbeit“. Beide Schreiben im Material Traber. (Privatbesitz Familie Traber, Hechingen). 
oder politisch verfolgt werden darf “5. Ansichten wie diese, die nichts mehr mit Schmids Auffassung einer reinen Ausschaltung politisch nicht mehr vertrauenswürdiger Elemente aus dem öffentlichen Leben zu tun hatten sowie stark von christlichen Normen wie innerer Umkehr, tätiger Reue und Vergebung geprägte Vorstellungen von einer angemessenen Entnazifizierung, haben Trabers Denken bestimmt. Und Anfang 1948 qualifizierte er die politische Säuberung in einem Zeitungsbeitrag so: „Die Entnazifizierung ist eine schwere Krankheit an unserem Volkskörper, die ihn erschüttert und die, wenn sie nicht gut behandelt und ausgeheilt wird, schwere Schäden für Volksgemeinschaft und Völkerverständigung zurücklassen kann" "6. Stand sein persönlicher Mut und sein Engagement im Umgang mit der Militärregierung ebenso außer Frage wie seine Loyalität zur Regierung Lorenz Bock, so geht aus seinen Akten, insbesondere den eigenhändigen Entwürfen, die Traber nach einem Jahr Amtsführung hinterließ (er starb am 4.6. 1948), doch hervor, daß er die Voraussetzungen für die Stellung eines Staatskommissars für die politische Säuberung wohl nicht in ausreichendem Maße besaß. Neben der Militärregierung waren auch nicht alle Kollegen von Trabers Eignung überzeugt ${ }^{7}$. Sein verblüffend ungelenker schriftlicher Ausdruck ${ }^{8}$ brachte einen führenden Beamten des Staatskommissariats beispielsweise dazu, den Akten anzuvertrauen, er habe keine Lust mehr, ,für die Presse einen von diesen verschlampten Artikeln" des Chefs zu überarbeiten".

Der Elan, mit dem die neue Landesregierung unter Lorenz Bock unmittelbar nach Amtsantritt die Generalrevision der politischen Säuberung in Württemberg-Hohenzollern ins Werk setzen wollte, stieß jedoch sofort auf den entschlossenen Widerstand der nach wie vor allein maßgebenden Autorität in Württemberg-Hohenzollern: Die Tübinger Militärregierung hatte ihre eigenen Vorstellungen vom Fortgang der Entnazifizierung. Dabei spielten für sie, läßt man die Motive für diese Haltung einstweilen noch beiseite, weder der Wortlaut der neuen Rechtsanordnung eine Rolle, noch die entscheidenden Nebenabreden und französischen Versprechungen, mit denen die Annahme des Spruchkammergesetzes der deutschen Landesverwaltung schmackhaft gemacht worden war; und es fiel ebenso wenig ins Gewicht, daß die mit großem Abstand führende Partei der Christdemokraten und die von ihr getragene Regierung diametral entgegengesetzte Vorstellungen einer künftigen politischen Säuberung hatte. Dem neu ernannten Staatskommissar war eine Statisten-, dem zurückgetretenen die Hauptrolle zugedacht. Dabei war wiederum Nebensache, ob Künzels Stellung innerhalb seiner ohnehin nicht mehr so einflußreichen Partei und sein inzwischen

${ }^{5}$ Privat-Schreiben v. 29.6. 1947; Material Traber.

6 Zweiteiliger Artikel des Staatskommissars v. 13.2.1948 für die Zeitungen „Schwabenecho“, "Schwäbisches Tagblatt“, „Schwäbische Zeitung“ und „Schwarzwälder Post“.

7 Vergl. die Aufzeichnung Künzels: „Neue Rechtsanordnung“; StA Reutlingen, Aktenverzeichnis 1945-1949, 211/212.

8 S. Trabers Schreiben an das Direktorium v. 5.7.1947 (SIG, Wü 13/227), seinen Entwurf für einen Appell an Gouverneur Widmer am 4. 8. 1947 (SIG, Wü 2, I, 610) und den Tätigkeitsbericht an Staatspräsident Bock - insbesondere vorletzter Absatz - v. 8. 11. 1947 (SIG, Wü 2, III, P 1016) 3).

9 Aktenvermerk v. 15.6. 1948; SIG, Wü 13/23. 
umstrittenes Image bei der Bevölkerung dies erlaubte oder nicht. Ergebnis dieser heraufziehenden Kontroverse, war sozusagen ein geräuschvolles Patt. Bis in das Jahr 1948 hinein, als auch von Baden-Baden aus die Integration der Zone in den Prozeß der Weststaatbildung nicht mehr aufgehalten werden konnte, war weder das Tübinger Gouvernement Militaire noch die Landesregierung in der Lage, sich ganz durchzusetzen. Der Sonderweg Südwürttembergs in der politischen Säuberung war trotz der Einführung des Spruchkammerverfahrens noch nicht beendet. Worin bestand nun diese Kontroverse und welche politischen Kräfte waren in diese nur mühsam entwirrbare Konfliktkonstellation - die Fronten der Auseinandersetzung verliefen keineswegs einfach zwischen Besatzungsmacht und Landesregierung - verwickelt?

Für die Militärregierung in Baden-Baden war, als sie ihren Gesetzentwurf in allen Ländern ihrer Zone durchgedrückt hatte, das Hauptziel einer einheitlichen und vorzeigbaren Entnazifizierungsregelung für das französische Besatzungsgebiet erreicht. Die praktische Umsetzung der Neuregelung blieb den regionalen Gouvernements überlassen, deren weitgehende Unabhängigkeit von der Zentrale bekannt und schon wiederholt kritisiert worden war ${ }^{10}$. So war es für die deutsche Seite kaum möglich und obendrein riskant, Proteste gegen etwaige Abweichungen von den Zusagen, die von den Gouverneuren auf Anordnung Baden-Badens bei den Verhandlungen um die Annahme des Spruchkammergesetzes gegeben worden waren, der zentralen Militärregierung direkt vorzutragen. Für die südwürttembergische Landesregierung in Tübingen lag Baden-Baden noch viel weiter entfernt als für die Délégation Supérieure, ein gangbarer Dienstweg führte für sie praktisch gar nicht dorthin. Die französische Militärregierung in Südwürttemberg hatte ihrerseits von Anfang an keinen Zweifel daran gelassen, daß sie die Neuordnung der politischen Säuberung nicht gerne sah. Sie war mit Qualität und Tempo der Entnazifizierung auf dem Verwaltungswege in den zurückliegenden Monaten im wesentlichen zufrieden gewesen und die im Vergleich zu Südbaden und Rheinland-Pfalz glänzende südwürttembergische Säuberungs-Statistik war ihrem politischen Kredit in Baden-Baden wohl auch zugute gekommen. Deswegen sah sie nun auch wenig Veranlassung, eine weitreichende Revision des Profils der politischen Säuberung in Württemberg-Hohenzollern hinzunehmen. Eine Generalrevision der bisherigen Ergebnisse in deutscher Alleinverantwortung hätte schließlich bedeutet, daß sich auch die Militärregierung praktisch von einem Tag zum anderen von ihren eigenen Kriterien distanzieren mußte. In einem Schreiben an die Landesregierung hob sie deshalb auch ausdrücklich hervor, sie müsse sich die maßgebliche Mitwirkung an den Einsprüchen gegen die Künzel-Urteile schon deshalb vorbehalten, weil diese Entscheidungen ja ,im Einvernehmen mit der Militärregierung getroffen“ worden seien ${ }^{11}$. Das deutsche Gegenargument, dem Gouverneur bleibe doch die Billigung der Urteile der Spruchkammern vorbehalten, vor denen die Revision verhandelt werden müßte ${ }^{12}$, fiel nicht auf fruchtbaren Boden, da auch in Südwürttemberg der beinahe automatische Rehabilitierungsmechanismus der „Mitläuferfabriken“ in der

10 Vergl. Henke, Aspekte, S. 185.

11 Schreiben der Milreg an den Staatspräsidenten v. 4. 8. 1947; SIG, Wü 2, I, 610.

12 So Staatspräsident Bock in der StaMiS 8. 8. 1947. 
US-Zone nicht unbekannt geblieben war. Doch nach den eindeutigen französischen Zusagen während der Verhandlungen um die Annahme des Spruchkammergesetzes, die nur als Generalvollmacht zu einer umfassenden Revision der alten Säuberungsergebnisse interpretiert werden konnten, setzte sich die Militärregierung in den Augen der deutschen Regierung jetzt auf alle Fälle ins Unrecht. Dieser Kurs war innerhalb des Tübinger Gouvernement Militaire offenbar auch nicht unumstritten. Die führenden Beamten der Rechtsabteilung, Zehler und Ebert, die angesichts der französischen Zusagen der parlamentarisch legitimierten Landesregierung weitgehendes Revisionsrecht zubilligen wollten, hatten sich allem Anschein nach aber nicht gegen den Leiter des „Service de l' Epuration“, Hauptmann Vigouroux, durchsetzen können ${ }^{13}$. Eine Parallele dieser typischen Frontstellung findet sich innerhalb des amerikanischen Military Government in den Auseinandersetzungen zwischen ,Special Branch“, die für die Entnazifizierung verantwortlich war, und der „Legal Division“.

Úber diesen restriktiven Kurs in der Frage der Revisionsregelung hinaus versuchte die Tübinger Militärregierung mit einer höchst fragwürdigen Variante, ihre eigenen Vorstellungen vom Fortgang der Entnazifizierung durchzudrücken: In der Hoffnung, damit bei weniger revisionsfreundlichen Kräften auf deutscher Seite Anklang zu finden, legte sie zunächst dem Staatssekretariat ${ }^{14}$ und dann nochmals der Landesregierung ${ }^{15}$ in einem gut verschleierten Angebot nahe, die Entnazifizierung in Württemberg-Hohenzollern hinter der Fassade des neuen Spruchkammergesetzes nach dem alten Verwaltungsverfahren, d. h. unter der Regie Künzels, zu Ende zu führen. Der Gouverneur empfahl nämlich - da die Entnazifizierung allgemein als kurz vor dem Abschluß befindlich betrachtet wurde -, alle bereits eingeleiteten Verfahren nach dem alten Säuberungsrecht von dem zurückgetretenen Säuberungskommissar entscheiden zu lassen, so daß, in den Worten Künzels, ,die neue Rechtsanordnung praktisch nicht zum Tragen" gekommen wäre ${ }^{16}$. Dieser Vorstoß entsprach ganz dem Konzept der Militärregierung, die gesamte Entnazifizierung in Württemberg-Hohenzollern nach dem Verwaltungsverfahren zu Ende zu führen und dessen Resultate nach Möglichkeit festzuschreiben, spottete aber dem elementaren Gedanken der Rechtssicherheit und verstieß auch eindeutig gegen Artikel 40 der - ordnungsgemäß in Kraft gesetzten Rechtsanordnung vom 25. April 1947, in dem es hieß, alle bei den Organen des Verwaltungsverfahrens anhängigen Verfahren ,gehen auf die nach dieser Rechtsanordnung zuständigen Untersuchungsausschüsse und Spruchkammern über" ${ }^{17}$

13 Vergl. die Notiz Trabers für den Staatspräsidenten v. 4. 8. 1947 und seinen Appell an den Gouverneur vom gleichen Tag; beides in SIG, Wü 2, I, 610.

${ }^{14}$ Schreiben des Gouverneurs an den Präsidenten des Staatssekretariats v. 27. 6. 1947; SIG, Wü 2, II, $611 / 3$.

15 Notiz über die Besprechung zwischen Staatspräsident Bock und dem Gouverneur am 5. 8. 1947; SIG, Wü 2, II, 8006.

16 Aufzeichnung Künzels: „Neue Rechtsanordnung“; StA Reutlingen, Aktenverzeichnis 1945-1949, 211/212.

17 Amtsblatt des Staatssekretariats für das französisch besetzte Gebiet Württembergs und Hohenzollerns, Nr. 26, S. 647. 
Der einzige Verbündete, der sich auf deutscher Seite zu diesem Manöver bereit finden wollte, war Künzel. Ohne Gespür für das seit 1945 gewandelte Klima glaubte er an die Chance, allein auf die Autorität der Militärregierung gestützt, seine Entnazifizierungslinie, die in sich ja durchaus diskutabel gewesen war, auch noch bei der in Württemberg-Hohenzollern nun einmal bestehenden politischen Konstellation durchsetzen zu können. Dabei hatte er sogar recht, wenn er rückblickend notierte, dieser Pakt mit der Militärregierung würde genau „dem ursprünglichen Vorschlag des damaligen Chefs der Landesregierung, Herrn Staatsrat Schmid,“ entsprechen ${ }^{18}$. In der Tat war Carlo Schmid, mit Unterstützung Gebhard Müllers, im November 1946 der Absicht Baden-Badens, das Spruchkammerverfahren auch in Südwürttemberg durchzusetzen, mit dem Vorschlag begegnet, gerichtsähnliche Spruchgremien in Südwürttemberg nur für die Nachprüfung des geringen Prozentsatzes klar erkennbarer Fehlentscheidungen Künzels - Schmid sprach noch Ende Juli 1947 von einer Marge von höchstens $5 \%{ }^{19}$ - und für die Aburteilung der Insassen der Internierungslager einzurichten. Diese Idee der Installierung von „Nachprüfungsinstanzen“ hatte damals, wie erinnerlich, auch bei der Tübinger Militärregierung Anklang gefunden und war von $\mathrm{ihr}$ - allerdings vergeblich - auch in Baden-Baden vertreten worden. Inzwischen war die Entwicklung allerdings längst über diesen Gedanken hinweggegangen; das neue Säuberungsgesetz war in Kraft und das Verwaltungsverfahren hatte nach der fortgesetzten Kritik der CDU zunehmend an Kredit in der Bevölkerung verloren. Jetzt galt das Spruchkammer-System wegen seiner justiz-ähnlichen Prozeduren als Standardverfahren, da es den zunehmend stärker in den Vordergrund gerückten Normen der Rechtsstaatlichkeit am ehesten zu genügen schien - ganz unabhängig von der Tatsache, daß die Spruchkammern die, Weißwäsche' wirklich Belasteter in der amerikanischen Zone überhaupt erst in Gang gesetzt hatten. Schon Ende 1946 hatte sich angedeutet, daß sich insbesondere die Sozialdemokraten in Regierung und Ministerialbürokratie dem Trend zu einer zunehmend milderen Beurteilung politischer Belastung aus der Zeit des Nationalsozialismus nicht würden entziehen können und daß sie Mühe hatten, das Spruchkammerverfahren, nach dem in Nordwürttemberg die Entnazifizierung abgewickelt wurde, den Betroffenen in Südwürttemberg vorzuenthalten, ohne sich dem Vorwurf unzeitgemäßer Härte auszusetzen. Die SPD in der Regierung hatte sich im Laufe der Beratung des Spruchkammergesetzes der CDULinie bereits stark angenähert, ehe der Oktroi des Militärregierungs-Entwurfes die ursprüngliche sozialdemokratische Auffassung wieder vorübergehend belebte, das Säuberungsverfahren auf dem Verwaltungswege habe in Württemberg-Hohenzollern doch eine positive Bilanz gezeitigt. Mitte 1947 aber konnte für die SPD die Wiederaufnahme einer überholten Idee auf dem Wege eines abenteuerlichen Zusammenspiels mit der Besatzungsmacht vor der Fassade des Gesetzes, das immerhin die Unterschriften Carlo Schmids und Viktor Renners trug, überhaupt nicht in Frage kommen. So beschloß das Staatssekretariat unter dem Vorsitz Carlo Schmids auf einer seiner letzten Sitzungen zwar die Einrichtung einer „Abwicklungsstelle“ unter Künzel, die die

18 Wie Anm. 16.

19 StaMiS 30. 7. 1947. 
büromäßige Aufarbeitung des alten Verfahrens und die Ausarbeitung der Urteilsbegründungen für die bereits entschiedenen Fälle zu erledigen hatte, bestimmte aber ausdrücklich: „Die Akten der bei ihm anhängigen, noch nicht durch eine Entscheidung abgeschlossenen Verfahren wird der Leiter der Abwicklungsstelle dem Staatskommissar aushändigen" ${ }^{\text {20 }}$. Damit hatte sich das Direktorium um Carlo Schmid vom Ansinnen der Militärregierung und von den Vorstellungen Künzels distanziert. Gegen die Errichtung der Abwicklungsstelle unter dem alten Säuberungskommissar waren in der Sitzung von Gebhard Müller und Staatskommissar Traber zunächst zwar Einwände erhoben, bald aber wieder zurückgezogen worden, denn in der Tat konnte die Aufarbeitung des alten Verfahrens - allein 10000 Fälle lagen noch zur Verhandlung bei der Militärregierung, 70000 Bescheide mußten noch an die Betroffenen versandt werden - von einem Neuling im Amt, der mit den gewachsenen Kriterien im Staatskommissariat nicht vertraut war, schlechterdings nicht bewältigt werden. Für die CDU, insbesondere nach ihrem überlegenen Wahlsieg, waren die Machinationen des Gouvernement Militaire natürlich gänzlich indiskutabel. Denn schließlich waren es vor allem die Christdemokraten gewesen, die die Entnazifizierung per Verwaltungsakt zunehmend schärfer als Willkür eines Funktionärs des linken Flügels einer Partei hinstellte, „,die kein Mittel unversucht läßt, ihre Vormachtstellung auf diesem prekären Gebiet der politischen Säuberung zu halten“21. Sie hatte ein Spruchkammerverfahren mit praktisch uneingeschränkten Revisionsmöglichkeiten angestrebt und die schließlich in Kraft gesetzte Rechtsanordnung galt dem CDU-Vorsitzenden gerade deshalb als ,,unbefriedigendes Gesetz “22, weil es in eben diesem Punkt weit hinter der Regelung in der amerikanischen Zone zurückblieb. Und Staatspräsident Bock, in seinem Denken undifferenzierter und konservativer als Gebhard Müller, hatte dem SPD-Staatskommissar noch nach dessen Rücktritt ja vorgeworfen, unter seiner Ägide seien ,einige tausend Fälle ungeheuerlich entschieden worden“ 23 .

In den Koalitionsverhandlungen hatte die CDU auch sogleich bedeutet, daß für sie eine Zusammenarbeit mit Künzel nicht in Frage komme ${ }^{24}$. Seine Ablösung, die politische Säuberung mittels eines ,gerechteren“ Verfahrens und die Revision der KünzelBescheide waren im Wahlkampf immer wieder als CDU-Forderungen aufgetaucht. Staatskommissar Traber beschwor förmlich die, wie er schrieb, „Vertrauenshausse“, die sich nun in der Bevölkerung ausbreite. Infolge der Änderung des Säuberungsver-

20 DirS 5. 7. 1947; Beschluß des Direktoriums über die „Abwicklungsstelle für die politische Säuberung nach der Rechtsanordnung v. 28. Mai 1946“.

21 So z. B. ein CDU-Landrat an die südwürttembergische Landesleitung der CDU in einem Schreiben, das von dort am 25. 2. 1947 an Gebhard Müller ging; StAL, Akten der LdJ, 2014-81/17.

22 Privater Brief Gebhard Müllers an Anton Traber v. 2. 7. 1947; Material Traber.

23 Notiz Künzels über eine Unterredung mit Staatspräsident Bock am 10. 10. 1947; StA Reutlingen, Aktenverzeichnis 1945-1949, 211/212. S. a. die Angriffe der CDU auf das alte Entnazifizierungssystem in Anwesenheit des Staatspräsidenten auf einer Versammlung in Rottweil Anfang September 1947; Schwäbische Zeitung v. 5. 9. 1947.

${ }^{24}$ Niederschrift über die Besprechungen zwischen SPD und CDU zur Regierungsbildung v. 29. 5. 1947; StA Reutlingen, Unverzeichnete Akten des Oberbürgermeisters Kalbfell, Ordner: Landtag 1947-1950. 
fahrens und des Wechsels an der Spitze des Staatskommissariats gehe „ein Aufatmen durch die Reihen der beteiligten oder auch nur ideell interessierten Kreise“ ${ }^{\text {" } 25}$.

Gebhard Müller, der abgewogener urteilte, weil er die verwickelten Probleme der Entnazifizierungspolitik genau kannte, hatte dem alten Säuberungssystem und auch Künzel selbst intern allerdings noch ein hervorragendes Zeugnis ausgestell ${ }^{26}$. Er war auch einer der ersten innerhalb der CDU, der dann später ,die kaum mehr zu verantwortende Milde“ der Spruchkammerurteile scharf kritisierte ${ }^{27}$. Es entbehrt nicht der Ironie, daß gerade er es gewesen ist, der mitten im Auflösungsprozeß der politischen Säuberung in Südwürttemberg, Ende 1948, gegen eine überdehnte Rechtsstaatlichkeits-Argumentation anging und als Staatspräsident das Recht der Exekutive gewahrt wissen wollte, selbst zu bestimmen, welche Beamten - gleichgültig wie der Revisionsbescheid der Spruchkammer aussah - wieder in den Staatsdienst aufgenommen werden sollten und welche nicht. Der Staatsgerichtshof für Württemberg-Hohenzollern verwarf dann jedoch das Gesetz, auf das die Regierung ihre Praxis stützte ${ }^{28}$, als verfassungswidrig ${ }^{29}$.

Schon in der ersten Woche nach Amtsantritt berief die Regierung Bock eine außerordentliche Kabinettssitzung zur Beratung der Entnazifizierung ein. Dieser ungewöhnliche und wohl auch demonstrative Schritt war ein Hinweis, daß die Regierung den Umschwung in der politischen Säuberung auch deutlich sichtbar zum Ausdruck bringen wollte: Gegen die Stimmen von Carlo Schmid und Eberhard Wildermuth (DVP) hob das Kabinett den Beschluß des Direktoriums, eine Abwicklungsstelle unter dem ehemaligen Staatskommissar zu schaffen, wieder auf. Die Weiterarbeit Künzels, selbst wenn sie nur büromäßiger Natur war, erschien dem Staatspräsidenten und den Ministern der CDU mit dem angekündigten Neuanfang in der Entnazifizierung offenbar unvereinbar ${ }^{30}$. Der „neue Geist, der Geist der individuellen Gerechtigkeit“" (Traber) ${ }^{31}$, der nach der Kaltstellung Künzels Einzug halten sollte, wurde durch eine Reihe ausgesprochen revisionsfreundlicher Zeitungsbeiträge des neuen Staatskommissars bekräftigt. Darin legte Traber dar, daß alle Betroffenen, deren Fall nach den im Gesetzestext verankerten Revisionsgründen eigentlich nicht mehr aufgegriffen werden konnte, nicht von der Revision ausgeschlossen bleiben sollte. Denn da der Staatskommissar ja in allen Fällen „,von sich aus die Revision anordnen“ könne, sollten sich Interes-

${ }^{25}$ Schreiben Trabers an das Staatssekretariat v. 5.7. 1947; SIG, Wü 13/227.

26 Wie Anm. 24.

27 StaMiS 10.12.1948.

28 Gesetz über die Regelung der Rechtsverhältnisse der aus politischen Gründen vom Amt entfernten Beamten v. 22.12.1948; Regierungsblatt für das Land Württemberg-Hohenzollern, Nr. 36, S. 181.

${ }^{29}$ Urteil des Staatsgerichtshofs für Württemberg-Hohenzollern v. 2. 7. 1951; AZ StGH 4 II 1/1950.

30 Auch der Geschäftsführer der Industrie- und Handelskammer Rottweil, der in Fragen der Entnazifizierung gut Bescheid wußte und von dem Vorstoß der Milreg Kenntnis erhalten hatte, wies Staatskommissar Traber darauf hin, ,daß es mit dem Geist der neuen Rechtsanordnung unvereinbar wäre, den bisherigen Staatskommissar mit der Abwicklung der noch nicht entschiedenen Fälle zu betrauen." Schreiben v. 15.7. 1947; SIG, Wü 13/259.

31 Schreiben Trabers an das Staatsministerium v. 8. 8. 1947; SIG, Wü 2, II, 611. 
senten einfach an ihre Dienststelle oder einen zuständigen Untersuchungsausschuß wenden ${ }^{32}$.

Die Militärregierung in Tübingen reagierte auf den großzügigen Einstand der neuen Landesregierung, die ihren Handlungsspielraum hier offenkundig überschätzt hatte, sofort mit ganzer Schärfe. Sie zwang die Regierung Bock, ihren Beschluß wieder rückgängig zu machen, es also bei der Abwicklungsstelle zu belassen, und korrigierte die deutschen Erwartungen hinsichtlich des Einspruchverfahrens. Alle deutschen Interventionen gegen diesen Befehl des Gouverneurs fruchteten nicht, und als Staatskommissar Traber in Reutlingen erschien, um gemäß Kabinettsbeschluß die Abwicklungsstelle von seinem Vorgänger zu übernehmen, mußte er unverrichteter Dinge wieder umkehren. Denn Künzel, der einen guten Draht zur Militärregierung hatte, erklärte ihm, er könne dem Beschluß des Staatsministeriums ,erst entsprechen, wenn die Zustimmung der Militärregierung vorliegt. Vorher nicht, und diese Zustimmung benötige ich schriftlich". Formal unzutreffend und provozierend, ansonsten aber die reale Situation völlig richtig kennzeichnend, verwies er auf die Quelle seiner Legitimation: „Ich bin nicht Beamter der deutschen Verwaltung gewesen, ich stand zwischen Beiden, ich bin verantwortlich gegenüber der Militärregierung und gegenüber der deutschen Regierung gewesen. Ihre Position ist eine andere" 33 . Am 8. August 1947 mußte Staatspräsident Bock seinen Ministern mitteilen, man habe sich der Anordnung der Militärregierung zu fügen und es bleibe „nichts anderes übrig, als den Beschluß vom 30.7. 1947 rückgängig zu machen"34.

Ihr Maximalziel, die politische Säuberung von Künzel hinter der Fassade des Spruchkammergesetzes zu Ende bringen zu lassen, hatte die Militärregierung nicht erreicht. Aber nachdem sie den Christdemokraten schon das Fanal der endgültigen Kaltstellung Künzels unter ziemlich peinlichen Umständen verwehrt hatte, richtete sie nun in der Entnazifizierungspolitik ihr Hauptaugenmerk darauf, den großzügigen Rehabilitierungskurs der Regierung zu blockieren. Hauptmann Vigouroux, in der Militärregierung einflußreicher Wortführer dieser Linie, gab Traber - ungeachtet dessen dramatischen, aber auch ein wenig ungelenken Appells an den Gouverneur ${ }^{35}$ - eindeutig zu verstehen, seine in der Präambel der Rechtsanordnung vom 25. 4. 1947 eingeräumten Befugnisse, Revision von Säuberungsentscheidungen einleiten zu können, werde, wie die schmucklose Wendung lautete, „im Einvernehmen mit der Militärregierung ausgeübt ${ }^{\text {"36 }}$. Die Bestürzung der Landesregierung war nur zu verständlich, denn allein die großzügig klingenden Einspruchsbefugnisse des Säuberungskommissars hatten die deutsche Seite seinerzeit zur Annahme der Rechtsanordnung bewegen können. Der

32 Vergl. Schwäbisches Tagblatt, Nr. 59, v. 25. 7. 1947, S. 5.

33 Niederschrift über die Besprechung mit Staatskommissar Traber am 4. 8. 1947 im Rathaus Reutlingen; StA Reutlingen, Aktenverzeichnis 1945-1949, 219.

34 StaMiS 8. 8. 1947.

35 Zweiseitiger Entwurf, o.D., vorgetragen auf dem Gouvernement Militaire in Tübingen am 4. 8. 1947; SIG, Wü 2, I, 610.

${ }^{36}$ Bestätigung der Vereinbarungen in der Besprechung mit Hauptmann Vigouroux am 6. 8. 1947 durch Schreiben Trabers an die Milreg v. 7. 8. 1947; SIG, Wü 2, I, 610. 
nun vorherrschende Eindruck, von der Militärregierung hinters Licht geführt worden zu sein, war nicht unberechtigt, denn die vorherige Genehmigungspflicht der Revisionsanträge durch die Besatzungsmacht stand tatsächlich, wie Gebhard Müller vor dem Kabinett bemerkte, ,,der feierlichen Zusicherung von Gouverneur Widmer entgegen, die er ihm anläßlich der Verhandlungen über die Rechtsanordnung gemacht habe “37. Auch wenn von Seiten der Militärregierung darauf verwiesen werden konnte, eine Revisionspolitik, die allein und pauschal für sämtliche Betroffenen auf die Abschwächung der ,Künzel-Bescheide hinauslaufe, entspreche ebenfalls nicht dem Geist der Präambel, so stand nun fest, daß das Recht des Säuberungskommissars in der Tat zum „Scheinrecht “38 geworden war. Das Vorgehen der Militärregierung zu korrigieren stand nicht in der Macht der Landesregierung, denn schließlich - und das hatten die Franzosen bei den Verhandlungen um die Annahme ihres Gesetzesentwurfes im März/April 1947 geflissentlich nicht angedeutet - war die politische Säuberung nach der Ordonnance Nr. 95 vom 9. Juni $1947^{39}$ eines der Gebiete, „welches sich die Besatzungsmacht ausdrücklich vorbehalten“ hatte. Nicht eine „diesbezügliche Bitte von Herrn Künzel", wie Arbeitsminister Eugen Wirsching (CDU) in der Kabinettssitzung $^{40}$ argwöhnte, hatte die Tübinger Militärregierung zu ihrem Sonderkurs bewogen, sondern ihr nicht ganz uneigennütziges Interesse, an dem ,good record“ der politischen Säuberung in Württemberg-Hohenzollern möge sich auch nach der Neuordnung der Entnazifizierung möglichst wenig ändern. So stand das ganze nächste Jahr die Frage, bis zu welchem Grad das Säuberungsprofil der Ära Künzel aufrecht erhalten oder wieder eingeebnet werden konnte, im Mittelpunkt der scharfen säuberungspolitischen Kontroverse zwischen Landesregierung und Militärregierung.

\section{Der Aufbau des Spruchkammerapparates}

Der Aufbau der neuen Säuberungsorgane in Württemberg-Hohenzollern begann, als das Spruchkammerverfahren im amerikanisch besetzten Nordwürttemberg schon in seiner „Endkrise“ steckte. Die Kritik an der Durchführung des Befreiungsgesetzes war in der US-Zone zunehmend heftiger geworden, der Entnazifizierungsapparat selbst befand sich „teils in Auflösung, teils im Widerstand gegen das Gesetz“41. Es konnte deshalb nicht überraschen, daß sich auch in Südwürttemberg kaum noch jemand bereit fand, in das diskreditierte Unternehmen einzusteigen. Obgleich die beteiligten Dienststellen die von Staatskommissar Traber benannten Personen, die nach Ausbildung und politischer Vergangenheit an sich für die Úbernahme einer Aufgabe bei der Entnazifizierung in Frage kamen, ,vorsorglich“ darauf aufmerksam machten, daß

\footnotetext{
37 StaMiS 8. 8. 1947.

38 Schreiben Trabers an das Staatsministerium v. 8. 8. 1947; SIG, Wü 2, II, 611.

39 J.O., S. 783.

40 Zitate aus: StaMiS 8. 8. 1947.

${ }^{41}$ Niethammer, Entnazifizierung, S. 483.
} 
nur „stichhaltige und schwerwiegende Gründe zu einer Ablehnung berechtigten “42, war das Resultat der Personalrekrutierung niederschmetternd. Neben dem generellen Mangel besonders an unbelasteten Juristen war den wenigen verbleibenden Kandidaten beinahe keine Begründung zu abwegig, um sich einer Nominierung zu entziehen. Der Präsident des Landgerichts Ravensburg beispielsweise mußte dem Staatskommissar berichten, daß die Benennung von Richtern auf „erhebliche Schwierigkeiten“ stoße ${ }^{43}$; er könne aus seirrem Bezirk, zu dem immerhin zehn Amtsgerichte gehörten, keinen einzigen Richter benennen. Einige seien bereits im vorgerückten Alter, einige völlig überlastet, alle übrigen müßten ,,als frühere $\mathrm{Pg}$ - wenn auch nur Mitläufer ausscheiden." Ein Richter habe dringend darum gebeten, ,,von ihm abzusehen, denn er habe aufgrund seiner Mitwirkung in dem bisherigen Ausschuß, obwohl er sich schon bemüht habe, den Betroffenen so gut wie möglich zu helfen, schon soviel $\mathrm{Haß}$ und Anfeindungen erfahren, daß er sich nicht mehr zu einer solchen Tätigkeit verstehen könne". Schon aus Rücksicht auf seine gemütsleidende Frau, die diese Angriffe aus der Nachbarschaft sehr schwer nehme, könne er bei der politischen Säuberung nicht länger mitwirken. Auch der Vorstand der südwürttembergischen Anwaltskammer konnte in drei Landgerichtsbezirken nur sechs Rechtsanwälte ausfindig machen, die die Voraussetzungen für den Spruchkammervorsitz mitbrachten, wies aber darauf hin, daß wohl kaum einer bereit sei, dies Amt auch zu übernehmen ${ }^{44}$. Sogar Berufsgruppen-Beisitzer waren kaum noch zu gewinnen. Einige Monate lang versuchte Traber vergebens, einen widerstrebenden Richter aus Rottenburg für dieses ,,wirklich bescheidene und anspruchslose Amt" zu gewinnen. Selbst der Versuch des Staatskommissars, ihn mit dem bemerkenswerten Eingeständnis, ,auch mir liegt meine jetzige Tätigkeit nicht", zu überreden, blieb erfolglos. Ganz offen begründete der Amtsgerichtsrat seine Ablehnung mit Bedenken, die bei vielen im Spiel gewesen sein dürften, die jetzt ihre Mitarbeit bei der politischen Säuberung verweigerten: „Bei meinen 56 Jahren ist meine gegenwärtige Dienststellung für das Entnazisieren [sic!] viel zu nieder; wen ich heute entnazisiere, der übt schon morgen direkt oder indirekt Aufsichtsbefugnisse über mich aus, gehöre er zu den Beamten oder zu den freien Berufen“ ${ }^{\text {45. }}$. Einem Freund klagte Traber im Herbst, von allen Seiten bekomme er zwar viel Kritik und kluge Worte zu hören, trete ,man dann an einen dieser Besserwisser und Könner

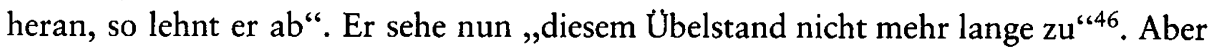
auch das Ende Dezember verabschiedete Dienstverpflichtungsgesetz ${ }^{47}$ konnte die

42 Schreiben der LdI an einen als Beisitzer in Aussicht genommenen Beamten v. 26. 6. 1947; SIG, Wü 42 P, acc. 10/1970, A 13150.

43 Schreiben v. 10. 7. 1947; StAL, Akten der LdJ, 2014-100.

44 Schreiben an die LdJ v. 26. 6. 1947; StAL, Akten der LdJ, 2014-98.

45 Ganzer Vorgang, 26. 8. 1947 bis 7. 9. 1948, in SIG, Wü 13/129.

46 Schreiben Trabers v. 18. 10. 1947 an Thaddäus Mayer, Riedlingen, der später selbst Staatskommissar für die politische Säuberung geworden ist; SIG, Wü 13/258.

47 „Gesetz über die Einführung der Dienstpflicht zum Zwecke der Durchführung der politischen Säuberung“ v. 12. 1. 1948; Regierungsblatt für das Land Württemberg-Hohenzollern, 1948, Nr. 11, S. 59. S. a. die Debatte des Landtags in der 13. Sitzung am 10. 12. 1947. 
durchgängigen „Entzugserscheinungen“ bei den Angehörigen der Verwaltung und in der Bevölkerung nicht beheben, sondern war nur sichtbarster Ausdruck behördlicher Ohnmacht. Niemand wollte mehr in die Prozeduren der Entnazifizierung hineingezogen werden, weder als Beisitzer in den Gremien, noch als Belastungszeuge. Aus der Mitte der Bevölkerung, der zumeist gar nicht bekannt war, daß inzwischen ein gerichtsähnliches Verfahren eingeführt worden war $^{48}$, kam trotz aller Kritik an den Säuberungsentscheidungen kein Belastungsmaterial mehr ${ }^{49}$. Der Standardvorwurf gegen die Entnazifizierung, man ,hänge die Kleinen und lasse die Großen laufen“, falle auf die Kritiker selbst zurück, meinte Traber, denn ,kein Mensch aus der Bevölkerung ist bereit, die Großen mir zu nennen und den Beweis zu erbringen, daß sie ,Große'

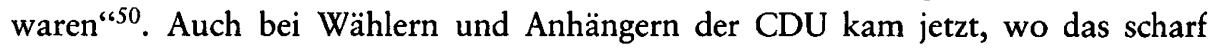
angegriffene Verwaltungsverfahren gefallen und das nach Auffassung der Christdemokraten gerechtere justizförmige Säuberungssystem auch in Südwürttemberg eingeführt war, kein rechtes Engagement auf. Unter diesen Umständen verstrich nach Inkrafttreten des Spruchkammergesetzes noch fast ein halbes Jahr, ehe die ersten Fälle vor den neuen Gremien verhandelt werden konnten.

Auch die praktische Unterstïtzung, die dem Staatskommissar in Organisations- und Beschaffungsfragen zuteil wurde, war ausgesprochen dürftig. Die Ressorts der Landesregierung - vom Justizministerium, das infolge der vielfältigen Aktivitäten Carlo Schmids faktisch von Gebhard Müller geleitet wurde, abgesehen - taten wenig, um den Aufbau der Säuberungsbehörde beschleunigen zu helfen. In einem längeren Rechenschaftsbericht Trabers an den Staatspräsidenten ist die desolate Randexistenz des Staatskommissariats innerhalb der deutschen Verwaltung förmlich mit Händen zu greifen. „Am 1. Juli [1947]“, so schreibt er, „trat ich das Amt an. Das Staatskommissariat bestand aus meiner Person allein. Kein Unterkommen, keine Beamten, kein Personal, kein Mobiliar, kein Material, rein gar nichts. Berge von Posteingängen kein Dienstwagen, nur auf das eigene Fahrrad angewiesen ... Verhandlungen und Rundschreiben mit allen Landratsämtern, Verwaltungen, Parteien und Gewerkschaften wegen Neuaufstellen der Ausschüsse und der Bildung von Spruchkammern. Wochenlange Verhandlungen mit deutschen Dienststellen und mit der Militärregierung wegen Ausquartierung der im [als Sitz des Staatskommissariats vorgesehenen] Gemeindehaus noch untergebrachten Litauer. Als diese Litauer das Haus verlassen hatten: Verhandlungen mit dem Bezirksbauamt und den Handwerkern wegen Herrichtung und baulicher Veränderungen. Als die Handwerker beginnen wollten, fehlten die Baumaterialien ... Kein Stuhl, kein Tisch, kein Schrank, nichts war vorhanden. Abends, bei Nacht und sonntags Ausarbeitung einer vorläufigen Dienstanweisung für die KRUAs und Spruchkammern ... All dies machte ich allein, da keinerlei Beamte oder Personal vorhanden war ... Manchmal erfüllt mich der Gedanke, ich könnte vor Vollendung der Organisation gesundheitlich zusammenbrechen, mit der größten Sorge. Es ist aber nicht meine Schuld, daß das Ganze nur auf 2 Augen steht [sic!] “51.

${ }^{48}$ Denkschrift eines Verwaltungsbeamten an den SK v. 28. 10. 1947.

49 Vergl. das Interview Trabers in der „Schwäbischen Zeitung“, Nr. 79, 3. 10. 1947.

so Wie Anm. 46.

s1 Schreiben Trabers v. 8. 11. 1947; SIG, Wü 2, III, P 1016/3. 
Der Vorwurf mangelnder Unterstützung, der in der mißglückten Formulierung des letzten Satzes mitschwingt, war auf die Ressorts der Landesregierung gemünzt, mit denen der Staatskommissar in ein monatelanges Tauziehen um die Gestellung von Personal und Material geriet. Doch mehrere Anforderungen der Staatskanzlei, zwei Kabinettsbeschlüsse sowie Ermahnungen seitens der Militärregierung ${ }^{52}$ blieben letztlich ohne große Resonanz. Als ein Beispiel für viele erklärte etwa das Kultusministerium Mitte Januar 1948, es sei „zu seinem Bedauern auch heute nicht in der Lage, irgendwelche Kräfte an andere Stellen abzugeben... Auch besteht hier ein erheblicher Mangel an Schreibmaschinen" 53 . Zur notdürftigen Besetzung der Entnazifizierungsgremien blieb schließlich nichts anderes übrig, als Beisitzer zu benennen, die im Zuge der politischen Säuberung selbst schon mit - wenn auch geringfügigen - Sühnemaßnahmen belegt worden waren ${ }^{54}$. Aber das Ergebnis der Suche nach geeignetem Personal, blieb, wie Traber nur leicht übertreibend an die Militärregierung schrieb, sehr oft „gleich Null“ ${ }^{\text {‘5 }}$. Für diejenigen, die sich überhaupt noch bereit fanden, beantragte er eine Zulage, weil diesen Kräften durch ihre Tätigkeit in den Säuberungsorganen eine zusätzliche Belastung erwachse: „Dazu komme die Unpopularität ihrer Tätigkeit“, referierte das Finanzministerium Trabers Begründung. „Es sei erforderlich, dem mit den undankbaren Aufgaben stark in Anspruch genommenen Personal gegenüber durch Gewährung einer Zulage die notwendige Anerkennung zuteil werden zu las-

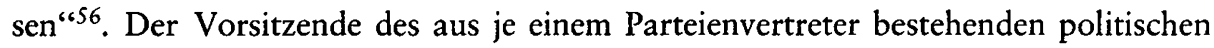
Beirats, der nach der Rechtsanordnung am Entnazifizierungsverfahren mitwirken sollte, war so taktvoll, in der Einflußlosigkeit des Säuberungskommissars dessen eigentliche Stärke zu entdecken. „Ich brachte ihm meine schon wiederholt dargelegte Ansicht zum Ausdruck“, so notierte er sich über eine Unterredung mit Traber, „daß er bei der Vertretung seiner Belange insofern eine günstige Position habe, als sich wahrscheinlich niemand für seine Nachfolgerschaft interessieren würde. Er kann also jederzeit die Kabinettsfrage stellen und damit letzten Endes die notwendige Unterstützung seiner Arbeit fordern und erhalten“"57. Inzwischen war die Militärregierung zunehmend ungeduldiger geworden. Denn trotz der formellen Eröffnung der ersten Spruchkammer im August ${ }^{58}$ arbeiteten die Kammern Anfang November 1947 immer noch nicht $t^{59}$. Schließlich machte die Militärregierung sogar persönliches Versagen Trabers für den schleppenden Aufbau der Entnazifizierungsgremien verantwortlich.

52 Vergl. Schreiben der Staatskanzlei an alle Ministerien v. 23.12.1947 und 22.1.1948 (SIG, Wü 42 P, acc. 10/1970, A 13150), die StaMiS v. 22.8.1947 und 11.1.1948 sowie GouvS 12.2. 1948 .

53 Schreiben v. 10.1.1948; SIG, Wü 80, acc. 10/1974, 56/126.

54 Vergl. das Schreiben des Kultusministeriums an den SK v. 12. 1. 1948 (SIG, Wü 80, acc. 10/1974, 56) und das Schreiben des Justizministeriums an den SK v. 20.1.1948; SIG, Wü 13/118.

55 Schreiben v. 16. 3. 1948; SIG, Wü 13/7.

56 Schreiben des Finanzministeriums an die Staatskanzlei v. 21. 2. 1948; SIG, Wü 2, I, 610/2 d.

57 Notiz v. 27.1. 1948; SIG, Wü 13/226.

58 Bericht Trabers an Milreg über die Eröffnung einer Spruchkammer in Tübingen am 26. 8. 1947; SIG, Wü 13/202.

59 Schreiben der Milreg an Traber v. 8. 11. 1947; SIG, Wü 2, III, P 1016/3. 
Er könne sich des Eindrucks nicht erwehren, meinte der Leiter der Säuberungsabteilung der Délégation Supérieure zu Lorenz Bock, ,,daß in letzter Zeit im Staatskommissariat für die politische Säuberung keine Ordnung mehr [verbessert aus: vollkommenes Chaos] geherrscht habe ${ }^{\text {600 }}$. Das war insofern nicht ganz gerechtfertigt, als es um den Aufbau des Säuberungsapparates in Rheinland-Pfalz und Baden nicht besser stand und der Staatskommissar die dilatorische Behandlung seiner Hilfeersuchen durch die Behörden selbst durch einen rastlosen persönlichen Einsatz nicht wettzumachen vermochte. Ende November konnte er dem Gouvernement immerhin anzeigen, daß die Spruchkammern ihre Tätigkeit aufgenommen hätten ${ }^{61}$. Doch bis die ersten Entscheidungen vorlagen, ging das Jahr 1947 zu Ende und am 1. März 1948 wies die Militärregierung nicht ohne Sarkasmus darauf hin, daß ihr bislang erst eine einzige erstinstanzliche Spruchkammer-Entscheidung vorliege ${ }^{62}$.

\section{Das Hauptproblem des neuen Verfahrens: \\ Die alten Entnazifizierungsurteile}

Durch die demonstrative Vereitelung der endgültigen Kaltstellung Künzels nach dem Regierungswechsel Mitte 1947 war schlagartig die Absicht der Tübinger Militärregierung deutlich geworden, die Revisionsfreudigkeit der Regierung Bock zu dämpfen und die Resultate des Entnazifizierungs-Modells der Landesverwaltung unter Carlo Schmid so gut es ging festzuschreiben. Doch die neue Landesregierung war - aus ihrer Sicht zweifellos mit guten Gründen - entschlossen, diese Herausforderung anzunehmen. Zum einen hatte das Gouvernement Militaire mit seiner Haltung einseitig die stillschweigende gemeinsame Geschäftsgrundlage verlassen, den deutschen Revisionsbestrebungen nach Annahme des aufgezwungenen Spruchkammergesetzes nichts in den Weg zu legen, zurn anderen konnte nach den Wahlergebnissen nur schlecht bestritten werden, daß der Revisions-Elan der CDU in der Bevölkerung eine breite Resonanz gefunden hatte, und schließlich war nicht einzusehen - am wenigsten von den Betroffenen -, weshalb die Spruchkammern in Südwürttemberg nicht die gleichen Eigenschaften haben sollten, die in der Nachbarzone schon seit mehr als einem Jahr erkennbar waren: als Entnazifizierungs-Organe zu firmieren, aber RehabilitierungsOrgane zu sein. Trotz des ständig präsenten Säuberungspathos in den öffentlichen Erklärungen des Säuberungskommissars ${ }^{63}$ bestand weder in der Entnazifizierungsbe-

${ }^{60}$ Aktenvermerk über eine Besprechung bei der Milreg am 12. 2. 1948; SIG, Wü 2, II, 8005.

${ }^{61}$ Schreiben des SK an Milreg v. 28. 11. 1947; SIG, Wü 13/203. „Mangels Vorsitzenden“ konnten drei der sechs Spruchkammern ihre Arbeit aber erst im April 1948 aufnehmen. Tätigkeitsbericht des SK für das 1. Quartal v. 15.4. 1948; SIG, Wü 13/25.

62 Bericht des politischen Beirats über eine Besprechung bei der Milreg; SIG, Wü 13/25.

${ }^{63}$ Rede anläßlich der Eröffnung der ersten Spruchkammer in Tübingen am 26. 8. 1947. Bericht des SK an die Milreg v. 28. 8. 1947; SIG, Wï 13/202. Zitat: „Wenn man erlebt hat und täglich neu erlebt, wie Militarismus und Nazismus das ganze Gefüge der Welt erschüttert und sie an den Rand allen Ruins gebracht haben, ist es einem eine Selbstverständlichkeit und ein Akt völkischen Selbsterhaltungstriebes, ich möchte sagen sowohl für uns als auch die übrige Welt, diese beiden Störenfriede und virulenten Spaltpilze abzutöten und auszuscheiden.“ 
hörde noch auch innerhalb der Landesregierung irgendein Zweifel daran, daß die Revision der Entnazifizierungs-Entscheidungen aus dem Verwaltungsverfahren - und zwar ausnahmslos zu Gunsten der Betroffenen - jetzt Priorität vor allen anderen Erwägungen genoß. Das Kultusministerium betonte die Erwartungen an das neue Verfahren noch einmal mit dem Hinweis, daß der Rehabilitierungsprozeß in Württemberg-Hohenzollern gegenüber der US-Zone ,um viele Monate im Verzug“ sei und für viele deswegen schon eine „schwere berufliche Schädigung“ eingetreten sei ${ }^{64}$. Lange bevor die ersten Spruchkammern ihre Tätigkeit aufgenommen hatten, stand ihre Funktion als Revisionsvehikel schon fest. Traber hatte dies wiederholt expliziert: „Die Reihenfolge, in der die Spruchkammern arbeiten,“ erläuterte er dem Innenministerium, ,, ist folgende: Dringlichkeitsstufe I: Alle Revisionsfälle, bei denen die Sühnemaßnahmen auf ,Entlassung ohne Bezüge', ,Beschäftigungsverbot', ,Vermögenskonfiskation' lauten. Von diesen werden diejenigen wieder zuerst behandelt, die schon am längsten zurückliegen. Dringlichkeitsstufe II: Alle Revisionsfälle, deren rasche Entscheidung von den Behörden gewünscht wird. Dringlichkeitsstufe III: Alle Revisionsfälle, in denen durch die Entscheidung die Existenz nicht unmittelbar bedroht ist. Dringlichkeitsstufe IV: Die übrigen Revisionsfälle aus der Verwaltung, Wirtschaft und Handwerk." Ganz zuletzt sollten, mit einer charakteristischen Einschränkung, auch noch Neufälle vor die Kammern kommen: „Soweit die Bearbeitung der Revisionsfälle es zuläßt, werden erstinstanzliche Fälle bearbeitet, die von den Behörden als

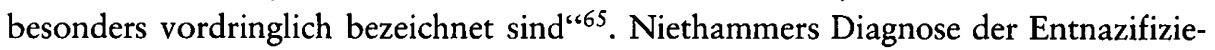
rung in der amerikanischen Zone trifft, lediglich zeitlich um ein Jahr versetzt, auch das Klima in Württemberg-Hohenzollern im Herbst 1947: Auch hier gab es auf der deutschen Seite praktisch niemanden mehr, der die Durchführung des Säuberungsgesetzes noch mit einer politischen „Säuberung verbinden wollte“666.

Die Entnazifizierungsbehörde in Tübingen, die den Kurs der Einebnung des Säuberungsprofils der Ära Künzel gegenüber der Militärregierung in tagtäglicher Auseinandersetzung zu vertreten hatte, stand vor einem mehrfach verschlungenen Problem. Die annähernd 80000 Fälle, die von Künzel entschieden und die nicht nach den jetzt üblich gewordenen fünf „politischen Typen“667 kategorisiert worden waren, mußten nun den Belastungsstufen der Kontrollratsdirektive Nr. 38 bzw. des Spruchkammergesetzes angeglichen werden. Diese „Umwertung“ der Künzel-Bescheide war unumgänglich, allein schon um die Vergleichbarkeit mit den in Südwürttemberg von den Spruchkammern neu zu entscheidenden Fällen und ebenso die Vergleichbarkeit mit Säuberungsurteilen aus den anderen Zonen zu gewährleisten; letzteres rückte im Zuge der verstärkten, die Zonen übergreifenden, Kontakte mehr und mehr in den Vordergrund. Außerdem war bei möglichen Amnestien nur so eine Gleichbehandlung aller

${ }^{64}$ Notiz des Kultusministeriums für den SK v. 16.9. 1947; SIG, Wü 13/271.

65 Schreiben v. 8. 12. 1947; SIG, Wü 13/244. Vergl. auch die ganz ähnlichen Ausführungen des SK in einer Notiz für die Besprechung mit dem südbadischen SK in Freiburg am 3. 11. 1947; SIG, Wü 13/523. $\quad{ }^{66}$ Niethammer, Entnazifizierung, S. 483.

${ }^{67}$ Schreiben von SK Junglas, Rheinland-Pfalz, an die dortige Milreg v. 22. 10. 1947; SIG, Wü 13/ 247. 
Fälle zu garantieren. Ganz zu recht stellte der Vorsitzende des politischen Beirats deshalb fest, daß diese Eingruppierung „eine der wichtigsten Aufgaben“ des neuen Säuberungsverfahrens sei: „Die Einstufung der politisch Belasteten in die eine oder andere Kategorie ist unter Umständen für ihre ganze spätere Existenz entscheidend und erfordert ein hohes Maß von Sorgfalt und Verantwortung "68. So hing von den Richtlinien zur Eingruppierung viel ab; eine Modifizierung in die eine oder andere Richtung mußte sofort die gesamte Entnazifizierungs-Bilanz verändern. In diesen Komplex der Einstufung war das Problem der Revisionsmöglichkeiten verwoben, die sich im Wortlaut der Rechtsanordnung vom 25. 4. 1947, in deren Präambel, und vor allem in den Zusagen der Militärregierung niedergeschlagen hatten. Bei den Revisionen waren die sogenannten gesetzlichen Revisionen und die Revisionen, die vom Staatskommissar von Amts wegen eingelegt werden konnten, zu unterscheiden. Erstere konnte jeder Betroffene einlegen, der durch Säuberungs-Urteil einer schweren Sanktion wie Entlassung, Berufsverbot oder mehr als $40 \%$-igem Vermögenseinzug unterworfen war. Der zusätzlichen Bedingung, neue Tatsachen beizubringen, falsche Zeugenaussagen im ersten Verfahren nachzuweisen oder dem Umstand, daß das Ersturteil mit den Kriterien des Spruchkammergesetzes unvereinbar sei, wurde in diesem Zusammenhang kaum Beachtung geschenkt. Die Rechtsgrundlage des zweiten Revisions-Typus, der Staatskommissar-Revisionen, war unsicherer. Sie ergab sich aus dem Wortlaut der Präambel, in der die ,,uneingeschränkte“ Befugnis des Säuberungskommissars festgelegt war, die Revision von Sühneentscheidungen anzuordnen, die ihm , übermäßig hoch oder zu niedrig“" erschienen ${ }^{69}$. Diese Befugnisse waren, wie ausführlich dargelegt, von der Militärregierung mehrfach bestätigt worden. Daß es dennoch keinen Sinn hatte, in der Revisionsfrage die Rechnung ohne die Militärregierung zu machen, war der deutschen Seite gleich nach Inkrafttreten der Rechtsanordnung drastisch genug vor Augen geführt worden. Immerhin konnte das Gouvernement Militaire den Bruch seiner Zusage mit dem Hinweis zu rechtfertigen versuchen, daß es dem Geist der Präambel nicht entsprach, wenn sich die Revisionsanträge des Staatskommissars ausnahmslos zu Gunsten der Betroffenen auswirkten.

Um keine weitere Verhärtung des Standpunktes der Militärregierung zu provozieren, vermied es Traber erst einmal, die Auseinandersetzung um das Revisionsrecht weiterzutreiben. Stattdessen versuchte er, die Initiative durch einen Vorstoß in der Frage der Einstufung der alten Entscheidungen in die Belastungsgruppen der neuen Rechtsanordnung wiederzugewinnen. Obgleich er sich bemühte, dies gegenüber der Militärregierung gar nicht erst anklingen zu lassen, war ihm natürlich nicht verborgen geblieben, daß die Regelung der Umgruppierung mindest ebenso viel Zündstoff enthielt wie die Kontroverse um die Revisionen. In zwei betont unpolitisch gehaltenen Schreiben ${ }^{70}$ machte er auf die Notwendigkeit der Einstufungen (,meines Erachtens mit eine der

68 Schreiben an den SK v. 28. 8. 1947; SIG, Wü 13/224.

69 Das an gleicher Stelle aufgeführte Revisionsrecht des politischen Beirats wird hier nicht berücksichtigt, da es in der Praxis keine Bedeutung gewinnen konnte.

70 Erstes Zitat aus dem Schreiben v. 29. 8. 1947, zweites aus dem Schreiben v. 30. 9. 1947; beide in: SIG, Wü 2, III, P 1016/3. 
Hauptaufgaben des neuen Staatskommissars") aufmerksam und fügte an, er könne sich denken, daß ,zu dieser Eingruppierung von zehntausenden von Fällen, da es sich nur um eine Verwaltungsmaßnahme handelt, nicht um eine Entscheidung und nicht um eine Abänderung der früher ausgesprochenen Sühnemaßnahme, die Militärregierung die Mitwirkung nicht beansprucht." Die Militärregierung teilte die Ansicht des Staatskommissars nicht. Sie hatte ebenfalls erkannt, daß bei entsprechender Handhabung der Einstufungen das gesamte bisherige Entnazifizierungsresultat durch einfachen Verwaltungsakt von Grund auf verändert werden konnte. Ihr nicht unbegründeter Argwohn gegenüber den weitgreifenden Revisionsanstrengungen der Landesregierung verleitete die Militärregierung zu einer Eingruppierungs-Anordnung für das „classement à posteriori“", die sich zwar völlig auf der eingeschlagenen revisionsfeindlichen Linie bewegte, sonst aber wenig durchdacht und praktisch undurchführbar war $^{71}$.

Im Erlaß des Gouvernement war bestimmt, daß die Höhe der Sanktionen, die vom ehemaligen Staatskommissar Künzel im Zuge des Verwaltungsverfahrens gegen die einzelnen Betroffenen ausgesprochen worden waren, das entscheidende und einzige Kriterium für die Eingruppierung in die fünf Belastungsgruppen des Spruchkammergesetzes sein sollte. Danach waren nun alle mit Internierung belegten Personen automatisch als „Hauptschuldige“ einzustufen. (Diese Bestimmung war in der Praxis ohne Bedeutung, weil von Künzel keine Internierungsmaßnahme verhängt worden war.) In die Gruppe der „Belasteten“ sollten alle eingereiht werden, gegen die auf Entlassung, Berufsverbot oder Vermögenseinzug von mehr als $40 \%$ bzw. Geldbuße von mehr als 15000 RM erkannt worden war. Alle, die eine erhebliche, jedoch unter dieser Marge liegende finanzielle Buße zu entrichten gehabt hatten und alle Beamten, die um mehr als 2 Dienstaltersstufen zurückversetzt worden waren, sollten in die Klasse der ,Minderbelasteten“ eingereiht werden. Als „Mitläufer“ sollte nur anerkannt werden, wessen Geldbuße unter 1000 RM gelegen hatte oder wer um höchstens 2 Dienstaltersstufen zurückgestuft worden war. Dieser Scheidelinie zwischen den „Mitläufern“ und den „Minderbelasteten“ galt natürlich das deutsche Hauptaugenmerk. Ihr Verlauf war schon deshalb von entscheidender Bedeutung, weil der Leiter der Militärverwaltung, Administrateur Général Laffon, den in Baden-Baden versammelten Ministerpräsidenten der französisch besetzten Länder in eben diesen Tagen eine baldige Amnestie für weniger Belastete angekündigt hatte ${ }^{72}$.

Auf deutscher Seite waren alle, einschließlich des Leiters der Abwicklungsstelle, sich einig, daß die Militärregierung mit dieser Anweisung die Scheidelinie zu den „Mitläufern" $\mathrm{zu}$ hoch angesetzt hatte. Eine rasch zusammengestellte erste Ubersicht ${ }^{73} \mathrm{ergab}$ daß nach dem vorliegenden Eingruppierungsschema in Südwürttemberg an die 60 Prozent aller Sanktionierten in die Gruppe der „Belasteten“ und „Minderbelasteten“ eingereiht werden mußten, wogegen in der US-Zone, ,die bisher im Rufe stand, in der

$\overline{71}$ Schreiben der Milreg an den Staatspräsidenten v. 20. 10. 1947; SIG, Wü 2, I, 610.

72 Ansprache an die Ministerpräsidenten am 21. 10. 1947; SIG, Wü 13/443.

${ }^{73}$ Statistische Erhebung in der Kultus- (SIG, Wü 80, acc. 10/74, 56) und Finanzverwaltung (vergl. StvS 27.10.1947). 
Entnazifizierung besonders scharf zu verfahren" - so ein Vertreter des Wirtschaftsministeriums ${ }^{74}$ - zu dieser Zeit etwa 90 Prozent der Fälle in der Kategorie der Mitläufer, nicht Betroffenen oder Entlasteten zu finden waren ${ }^{75}$. Da dieser Einstufungserlaß in Südwürttemberg plötzlich einen derart hohen Prozentsatz der vom Entnazifizierungsverfahren Betroffenen zu „Belasteten“ und „Minderbelasteten“ gestempelt hätte, war die Anordnung der Militärregierung für die deutsche Seite natürlich gänzlich indiskutabel $^{76}$. Und ganz zu recht warnte Staatskommissar Traber, bei der inzwischen allgemein üblich gewordenen Qualifizierung politischer Belastung nach den Kriterien der Kontrollrats-Direktive Nr. 38 und der Spruchkammergesetzgebung ergäbe sich ,ein historisch ganz falsches Bild von der Beteiligung des Volkes am Nazismus“, das ,für immer festgehalten" würde ${ }^{77}$.

Das sachlich nicht lösbare Dilemma, vor dem Besatzungsmacht wie Landesregierung nun standen, lag in der prinzipiellen Unvergleichbarkeit der beiden EntnazifizierungsSysteme begründet, die in Württemberg-Hohenzollern einander abgelöst hatten. Deren nach ganz unterschiedlichen Kriterien getroffene Säuberungs-Entscheidungen konnten nicht in eine sinnvolle Konkordanz gebracht werden. Die Urteile Künzels resultierten aus politisch motivierten Zweckmäßigkeitserwägungen. Sie sollten durch ihre Haltung gegenüber dem Nationalsozialismus Kompromittierte, ohne Berücksichtigung der inneren Tatseite, dort ausschalten, wo sie nach Auffassung der Landesverwaltung die Neuorganisation des demokratischen Gemeinwesens zu gefährden drohten. Im Spruchkammerverfahren war dagegen von gerichtsähnlichen Organen der Grad der individuellen Verantwortlichkeit - ganz unabhängig von den gegenwärtigen Einflußmöglichkeiten - nach quasi-juristischen Tatbestandsmerkmalen zu ermitteln, die dann jeweils zugeordnete Sühnemaßnahme nach sich ziehen konnten. An beliebig ausgewählten Beispielen ließ sich zeigen, daß es unmöglich war, nach den verhängten Sanktionen im ersten Verfahren den Grad der politischen Belastung nach den Maßstäben des zweiten zu bestimmen. So konnte etwa von der Höhe der Geldbuße nicht auf die politische Belastung geschlossen werden, weil für deren Bemessung meist die Höhe des Einkommens maßgebend gewesen war. Einer, der 10000 RM zu zahlen hatte, konnte demnach politisch weniger belastet sein als einer, der nur $2000 \mathrm{RM} \mathrm{zu}$ entrichten gehabt hatte. $\mathrm{Zu}$ ebenso widersinnigen Konsequenzen hätte die Eingruppierung nach der Sühnemaßnahme „Versetzung in den Ruhestand“ geführt, weil diese Maßnahme bei älteren Beamten häufig auch bei nur geringfügiger Belastung angeordnet worden war. Die rund $50 \%$ der Beamten, die wegen ihres frühen Beitritts zu NSDAP von Künzel meist um drei bis vier Dienstaltersstufen zurückversetzt worden waren, wären nun zu „Minderbelasteten“ geworden - eine Qualifizierung, die ihrerseits aber

\footnotetext{
74 Aktenvermerk für die Kabinettssitzung am 23.10.1947; SIG, Wü 140, 76/6000.

75 StvS 27. 10. 1947.

76 Vergl. die einmütige scharfe Ablehnung des Milreg-Erlasses durch den Staatspräsidenten (StaMiS 23. 10. 1947), den Leiter der Staatskanzlei, G. H. Müller (22. 10. 1947; SIG, Wü 2, III, P 1016/ 3), den SK von Rheinland-Pfalz (wie Anm. 67) und die Stellvertreter der Minister (StvS 27. 10. 1947).

77 Schreiben des SK an den Staatspräsidenten v. 8. 11. 1947; SIG, Wü 2, III, P 1016/3.
} 
unter Berücksichtigung der Definition des „Minderbelasteten“ im Spruchkammergesetz grob ungerecht gewesen wäre. Ganz abgesehen davon, daß sich die „Herausstellung eines im Dienst befindlichen Beamten als ,Minderbelasteter “", so die Stellvertreter der Minister in einer Besprechung, nicht mit dem Ansehen und öffentlichen Vertrauen vertrage, ,das ein Beamter zur Führung seines Amtes benötige“78.

$\mathrm{Da}$ die von der Besatzungsmacht aufgestellten Einstufungsgrundsätze „offensichtlich nicht tragbar" waren, wie Staatspräsident Bock im Kabinett nochmals betonte, wurde beschlossen, der Besatzungsmacht mit einem Kompromißvorschlag entgegenzutreten, der die deutschen und die französischen Vorstellungen zu verbinden suchte ${ }^{79}$. Sein materieller Gehalt basierte auf einem Vergleich der Säuberungsentscheidungen Künzels mit dem Ergebnis der Entnazifizierung in der amerikanischen Zone. Demnach mußte das Säuberungsprofil in Nordwürttemberg und Südwürttemberg annähernd gleich ausfallen, wenn die Scheidelinie zwischen den „Mitläufern“ und den drei schwereren Belastungsgruppen so gelegt würde, daß alle, die um höchstens drei Dienstaltersstufen zurückversetzt bzw. mit einer höchstens 10-prozentigen Vermögensabgabe belegt worden waren, zu Mitläufern wurden. Die Fälle der Gruppen I bis III sollten von den Spruchkammern bzw. deren Vorsitzenden klassifiziert werden. Ihnen wurde ein vierzehntägiges Einspruchsrecht eingeräumt. Als Mitläufer sollten Betroffene eingestuft werden, die die vorgesehenen Kriterien erfüllten, ,durch Feststellungsvermerk seitens des Spruchkammervorsitzenden“. Es lag auf der Hand, daß dieser Vorschlag nicht den Ansprüchen entsprach, die von der Landesregierung selbst immer wieder öffentlich an ein rechtsstaatlichen Grundsätzen genügendes Verfahren gestellt worden waren. Die Gewinnung von Einstufungskriterien im Analogieschluß mit Hilfe statistischer Größen entsprach keineswegs der im geltenden Säuberungsgesetz vorgeschriebenen gerechten Abwägung der individuellen Verantwortlichkeit des Betroffenen. Dieser Vorschlag benachteiligte außerdem generell die Betroffenen, die im Verwaltungsverfahren der politischen Säuberung unterzogen worden waren, gegenüber denen, die jetzt das Verfahren vor den Spruchkammern mit all seinen Rechtsgarantien durchlaufen konnten. Eine nach den immer wieder herausgestellten Maßstäben der Regierung Bock wirklich vertretbare Umwertung der Künzel-Entscheide wäre allein auf dem Wege der Neuverhandlung aller Urteile vor den Spruchkammern möglich gewesen. Denn immerhin verbarg sich hinter dem harmlos klingenden Terminus der „Eingruppierung“ in den meisten Fällen eine ,,ausgesprochen rechtsschöpferische Tätigkeit“"80.

Die Zurückweisung der nicht durchdachten Anweisung der Besatzungsmacht zur Einstufung der alten Entnazifizierungs-Urteile durch die Landesregierung war sachlich geboten. Ebenso war die Orientierung der deutschen Gegenvorschläge an den Säuberungsresultaten der amerikanischen Zone zwar plausibel, kontrastierte aber mit den immer wieder formulierten Ansprüchen an ein rechtsstaatlich geordnetes Entnazi-

\footnotetext{
78 StvS 27. 10. 1947.

79 Enthalten im Schreiben des SK an Milreg v. 31. 10. 1947; SIG, Wü 2, III, P 1016/3.

80 Wie Anm. 67.
} 
fizierungsverfahren. Doch in einer Zeit, in der sich die politische Säuberung nur noch in der Suche nach dem zügigsten Verfahren zur Liquidierung eines unbequem gewordenen Erbes aus den beiden ersten Jahren nach dem Zusammenbruch erschöpfte, nahm an solchen Widersprüchen niemand mehr Anstoß. Der Anschein, auch im Eingruppierungsverfahren die Maximen einer justizförmigen Entnazifizierung nicht zu verlassen, war in dem Gegenvorschlag der Landesregierung, der alle Züge eines Kompromisses trug, sogar gewahrt worden. Dem Kabinett war klar gewesen - und man hatte die Erfahrung ja schon früher gemacht -, daß etwa die Forderung nach einer Neuverhandlung der Künzel-Bescheide überhaupt keine Chance hatte, von der Militärregierung akzeptiert zu werden. Den Besatzungsbehörden in Tübingen, die sich schon aus Prestigegründen nicht ohne weiteres von ihrem nicht praktikablen Vorschlag - es war in den drei Jahren der politischen Säuberung nicht der erste - distanzieren konnten, dürfte die deutsche Weigerung, den Erlaß buchstabengetreu durchzuführen, als Bestätigung ihres Eindrucks erschienen sein, daß der Landesregierung jedes Mittel recht sei, die Revision der bisherigen Säuberungsergebnisse so umfassend wie möglich zu gestalten. Andererseits mußte die Militärregierung einsehen, daß die Forderung der deutschen Seite, wenigstens die schwereren Fälle durch Spruchkammern eingruppieren zu lassen, nicht unbillig, unter dem Gesichtspunkt der Gleichbehandlung aller Betroffenen in Südwürttemberg sogar eine Minimalforderung war. Ein Zugeständnis seitens der Militärregierung in dieser Frage hätte aber bedeutet, daß die wenigen mühevoll installierten Spruchkammern, die mit den Revisionsanträgen ohnehin schon ausgelastet waren, auf unabsehbare Zeit durch die Bearbeitung der Eingruppierungen verstopft sein würden; an einen raschen Abschluß der Entnazifizierung, der auch von den Franzosen immer wieder gefordert wurde, war dann nicht mehr zu denken. Spät - und in Württemberg-Hohenzollern ganz besonders deutlich rächte sich nun, daß die Besatzungsmacht ihrer Zone, ohne daß es die Sache der Entnazifizierung wirklich erfordert hätte, aus interalliierten Rücksichten das Spruchkammerverfahren hatte überstülpen müssen. Der Knoten, der sich hier geschürzt hatte, war nur noch durch einen radikalen Schnitt zu lösen. Früher oder später war auch die Militärregierung in der französischen Zone gezwungen, das ganze Verfahren durch eine Amnestie zu beschleunigen.

Einstweilen gab es in Tübingen aber keine Anzeichen dafür, daß die Militärregierung von ihrem Erlaß wieder abzurücken gedachte. Während Gouverneur Widmer gegenüber dem Staatspräsidenten die Tür zu weiteren Verhandlungen nicht zuschlagen wollte $^{81}$, holte sich der Säuberungskommissar bei dem spiritus rector der Kräfte innerhalb der Besatzungsbehörde, die den deutschen Revisionsbestrebungen keinerlei $\mathrm{Zu}$ geständnisse machen wollten, mit seinen Gegenvorschlägen eine drastische Abfuhr. Hauptmann Vigouroux, so berichtete Traber, habe ihm in ,ziemlich erregter Weise“ bedeutet, daß der Einstufungs-Erlaß ohne Abstriche raschest durchgeführt werden müsse. Dem Hinweis auf die groben Ungerechtigkeiten des befohlenen Verfahrens stellte Vigouroux Kategorien historischer Gerechtigkeit gegenüber: Er erinnere daran,

81 StaMiS 31. 10. 1947. 
daß die „bei der Eingruppierung entstehenden Ungerechtigkeiten lange nicht so groß seien, wie die von den deutschen Sondergerichten und Hitler begangenen". Solche Argumente konnten in dem inzwischen erreichten Stadium weitgehender Jurifizierung der politischen Säuberung niemanden mehr erreichen, denn was, so hätte ein in seinem Besoldungsdienstalter zurückversetzter Beamter zweifellos entgegnet, hatte er mit dem Unrechtsystem Hitlers und der Sondergerichte zu schaffen gehabt? Als einzige Möglichkeit, der starren Haltung der Tübinger Militärregierung zu begegnen und „Recht und Gerechtigkeit im Säuberungsverfahren “ zu erreichen, bleibe nun wohl nur noch, sich direkt an Baden-Baden zu wenden und zu erkunden, ob dort derselbe „unnachgiebige Standpunkt" eingenommen würde ${ }^{82}$.

\section{Blockade der französischen Amnestieverordnung durch die Tübinger Militärregierung}

Am 17. 11. 1947 - die Standpunkte in der heftigen Auseinandersetzung zwischen der Militärregierung in Tübingen und der deutschen Landesregierung um die weitere Behandlung der Entnazifizierungsbescheide der Ära Künzel lagen nach wie vor weit auseinander - erließ das Commandement en Chef Français in Baden-Baden die angekündigte „Verordnung Nr. 133 über die Entnazifizierung“83. Sie wurde bald allgemein als Amnestie-Verordnung bezeichnet. Darin waren die Regierungen der deutschen Länder in der französischen Zone aufgefordert, alle erforderlichen Maßnahmen zu ergreifen, damit die Säuberungsorgane von dem Ballast der Bagatellfälle befreit würden und sich endlich den schwerer Belasteten zuwenden könnten ${ }^{84}$. Deshalb durften ab sofort „keine Säuberungsmaßnahmen gegen die einfachen, nominellen Mitglieder der Nationalsozialistischen Partei und der ihr angeschlossenen Verbände ergriffen werden, die in diesen weder einen Titel noch ein Amt innehatten". Diese Gruppe sollte wieder in „den Genuß ihrer politischen und bürgerlichen Rechte“ gelangen. Vom südwürttembergischen Staatskommissar wurde diese in der Öffentlichkeit von hohen Erwartungen begleitete Verordnung prinzipiell begrüßt. Sie werde wohl ,eine große Erleichterung und Beschleunigung für das Verfahren und die Betroffenen brin-

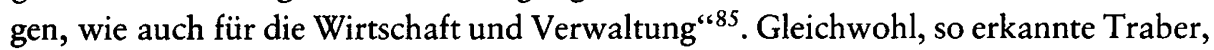
werde die Durchführung der Amnestie gerade in Württemberg-Hohenzollern mit einem erheblichen Arbeitsaufwand verbunden sein, da wegen der besonderen Definition der Amnestierten-Gruppe „Fall für Fall der 80000 darauf hin geprüft werden“

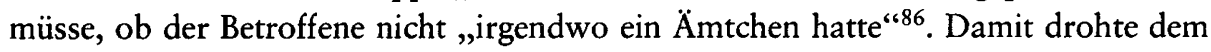

\footnotetext{
82 Schreiben Trabers an den Staatspräsidenten v. 8. 11. 1947; SIG, Wü 2, III, P 1016/3.

${ }^{83}$ J.O., S. 1244.

84 Als solche hatten nach Art. 2 der VO Nr. 133 ,die Mitglieder der durch das Nürnberger Urteil für verbrecherisch erklärten Organisationen sowie die leitenden und hauptsächlichsten aktiven Mitglieder der Nationalsozialistischen Partei und ihrer angeschlossenen Verbände“" zu gelten.

85 Stellungnahme des SK zur VO Nr. 133 v. 27. 11. 1947; SIG, Wü 13/444.

${ }^{86}$ Schreiben Trabers an den Staatspräsidenten v. 25.11. 1947; SIG, Wü 13/514. An diesem Tage war die VO in Württemberg-Hohenzollern bekannt geworden.
} 
Säuberungsapparat, wenn er seine Arbeit erst einmal aufgenommen hatte, in der Tat die vollständige Verstopfung mit Bagatell- und Revisionssachen - gerade das Gegenteil davon, was die Militärregierung mit der Verordnung erreichen wollte. Auf deutscher Seite galt es als ausgemacht, und der Staatskommissar hatte die Kammern auch in diesem Sinne angewiesen, daß der Behandlung der Revisionen die absolute Priorität einzuräumen war. (Nebenbei bemerkt war dieser Revisionsdruck in Südwürttemberg sachlich noch weniger plausibel als in der amerikanischen Zone, wo bis zum rechtskräftigen Urteil der Spruchkammer Beschäftigungsverbot bestand ${ }^{87}$.) Durch die Verordnung 133 wurde der Entnazifizierungsapparat zusätzlich mit der Aufgabe belastet, festzustellen, wer nicht mehr vor den Spruchkammern zu erscheinen brauchte und wer unter den zehntausenden von bereits entschiedenen Fällen seine ,politischen und bürgerlichen Rechte" wiedererlangt hatte. Besonders der letzteren Aufgabe konnten sich die Säuberungsorgane unter dem Druck der Öffentlichkeit keinesfalls entziehen. Für die bevorzugte Behandlung schwer Belasteter im Sinne der französischen Verordnung blieb so kein Raum mehr.

Neben dieser quasi strukturellen Schwäche war die Verordnung 133 auch so unpräzis abgefaßt, daß sie ohne Durchführungsbestimmungen „unklar und deswegen beinahe unanwendbar" bleiben mußte ${ }^{88}$. Doch wie auf deutscher Seite herrschten auch bei der Militärregierung in Tübingen ,nicht minder große Zweifel und Unklarheiten “89. Dem Staatskommissar fiel - angesichts der bereits schwer getrübten Beziehungen zur Besatzungsbehörde - die undankbare Aufgabe zu, dem Gouvernement Militaire die Mängel der Baden-Badener Verordnung im einzelnen vor Augen zu führen ${ }^{90}$. Aus der Anweisung ging beispielsweise nicht hervor, welche Personengruppe mit ,leitende und hauptsächlichste aktive Mitglieder“ der NSDAP gemeint und was unter „Titel“ und „Amt" exakt zu verstehen sei. Ebenso ergab sich aus dem dritten Artikel die widersinnige Konsequenz, daß ein Nicht-Parteigenosse, der bei einer Gliederung oder Organisation ein Amt inne hatte, nicht unter die Vergünstigung falle, ein Parteigenosse dagegen, dem es gelungen war, jedes Amt ,von sich abzuweisen, unter die Vergünstigung falle“. Wie hinsichtlich der Sühneleistungen bereits Entnazifizierter zu verfahren sei, gehe ebenfalls nicht aus dem Text hervor: „Es würde von den Entnazifizierten als ein sehr großes Unrecht und als eine sehr große Härte angesehen werden, wenn die gegen sie erkannten Sühnemaßnahmen bestehen bleiben würden, während den künftig zu Behandelnden und unter die Vergünstigung fallenden Betroffenen überhaupt keine Sühnemaßnahmen mehr auferlegt würden. "Zum Schluß seiner vierzehn Punkte umfassenden Mängelliste berührte Traber einen neuralgischen Punkt, als er darauf hinwies, daß sich die Nominellen-Amnestie ,ganz erheblich“ mit dem Problem der Eingruppierung der Künzel-Bescheide überschnitt. Dazu führte er ein einleuchtendes Beispiel an: „Ein nomineller Pg., der mit 20000 RM Geldbuße wegen seines hohen Vermögens belegt worden ist, und nach dem Brief [der Militärregierung]

87 Vergl. Art. 58 BefrG.

88 Schreiben Trabers an einen Geschäftsmann v. 20. 12. 1947; SIG, Wü 13/248.

89 Schreiben des SK an den Kreispräsidenten von Lindau v. 5. 12. 1947; SIG, Wü 13/443.

${ }^{90}$ Schreiben Trabers an die Milreg v. 1. 12. 1947; SIG, Wü 2, II, 611. 
in die Gruppe der Schuldigen einzureihen wäre, könnte nach der neuen Verordnung als Entlasteter herauskommen, denn die neue Verordnung stellt ja in keiner Weise auf die bereits anerkannte Sühnemaßnahme ab, sondern nur auf die einfache nominelle Mitgliedschaft ohne Amt und Titel. Es dürfte auch nicht gewollt sein, daß man sich jetzt um eine Eingruppierung in die Gruppe der Mitläufer und Minderbelasteten bemüht, um nachher festzustellen, daß diese Eingruppierten nach der Verordnung Nr. 133 nun Entlastete sind. " Der völlig gerechtfertigte, für die Militärregierung aber zweifellos peinliche Hinweis Trabers auf dieses „Kuriosum “91, das sich nun aus der unkoordinierten und konfusen Säuberungspolitik der französischen Besatzungsmacht ergeben hatte, dürfte auch der Entnazifizierungsabteilung der Tübinger Militärregierung vor Augen geführt haben, daß sie mit ihrem Kurs, die Konsequenzen, die sich aus der Einführung des Spruchkammerverfahrens in der französischen Zone ergaben, für Württemberg-Hohenzollern nicht zu akzeptieren, auf lange Sicht auf verlorenem Posten stand. Es dürfte ihren hinhaltenden Widerstand gegen die Aufweichung des Säuberungsprofils der Ära Künzel aber angestachelt haben, daß Traber als deutsche Empfehlung den kühnen Vorschlag machte, die Verordnung 133 sogleich wieder fallen zu lassen und statt dessen eine generelle Amnestie für alle in die Gruppe der „Mitläufer“ und „Minderbelasteten“ einzureihenden - gleichgültig, ob sie „Amt oder Titel" innegehabt hatten - zu erlassen. Tatsächlich war dies ein halbes Jahr später genau der Weg, den die französische Zonen-Militärregierung einschlug, um die politische Säuberung auch formell zu liquidieren. Doch jetzt, Ende des Jahres 1947, da sich die Auseinandersetzung zwischen Besatzungsmacht und Landesregierung auch noch in anderen Bereichen verschärfte, überforderte der Säuberungskommissar mit seinem Vorschlag nicht nur die Kompetenzen der regionalen Besatzungsbehörde, sondern er bestärkte sie geradezu in ihrer - durchaus zutreffenden - Auffassung, daß es der Landesregierung gar nicht schnell genug gehen könne, bis praktisch alle von den Säuberungsbescheiden der Ära Künzel Betroffenen in Mitläufer verwandelt, amnestiert und damit von allen Rechtsfolgen befreit waren.

Der Tübinger Militärregierung, die ihren Widerstand gegen die Verwässerung der Künzelschen Säuberungsergebnisse noch nicht aufzugeben gedachte, erwuchs in dem Amnestie-Erlaß ein willkommenes Druckmittel. Dabei verstand sie es auch, sich die Erklärungsbedürftigkeit der Verordnung Nr. 133 zunutze zu machen. Solange die Durchführungsbestimmungen der Verordnung noch nicht aus Baden-Baden bei ihm eingetroffen seien, meinte der Kabinettschef des Gouverneurs gegenüber Lorenz Bock $^{92}$, könne er zwar über deren Handhabung noch nichts sagen, es liege aber ganz im deutschen Interesse, die Eingruppierung der alten Säuberungsentscheide inzwischen „möglichst schnell durchzuführen, damit die kleinen Nazis in den Genuß der neuen Amnestie kommen“. Die Landesregierung, die die Mängel der Verordnung kannte, mußte einsehen, daß bis zum Erlaß der Durchführungsrichtlinien in der Amnestiefrage keine praktischen Maßnahmen eingeleitet werden konnten. Während die-

91 Traber in einem Schreiben an den Staatspräsidenten v. 25. 11. 1947; SIG, Wü 13/514.

92 GouvS 26.11. 1947. 
ses Moratoriums versuchte die Militärregierung in Tübingen noch einmal alles, um ihre Vorstellungen durchzusetzen. Dem Staatskommissar wurde bedeutet ${ }^{93}$, er solle seinen Widerstand aufgeben und „die Eingruppierung nun schleunigst auf der Grundlage des Briefes der Militärregierung vornehmen". Zweifelsfälle könnten einstweilen zurückgestellt werden. Um ein Höchstmaß an Beschleunigung zu erreichen, wurde Traber vom Leiter der französischen Entnazifizierungs-Abteilung zu einem rein schematischen Vorgehen gedrängt: „Ich solle es machen wie ich wolle“, habe ihm Vigouroux erklärt, ,ich könne ja das Amtsblatt zur Hand nehmen und an Hand des Amtsblatts die Eingruppierung vornehmen". Nicht ohne auf die zahlreichen Fehlerquellen dieses Eilverfahrens hingewiesen zu haben, akzeptierte der Staatskommissar schließlich den Vorschlag, weil sich hier eine Aufweichung der starren Fronten in der Frage der Einstufungen abzuzeichnen schien. Denn, so dürften die Überlegungen nun gewesen sein, wenn die Militärregierung bereit war, die Zweifelsfälle erst einmal auszuklammern, dann bedeutete dies möglicherweise, daß jetzt das EingruppierungsTempo Vorrang vor der exakten Einhaltung des angeordneten EingruppierungsModus erhalten hatte. Allerdings lag in dem Eilverfahren, das jetzt ohne Aktenprüfung allein an Hand der im Amtsblatt abgedruckten Sühnemaßnahmen durchzuführen war, die Gefahr - aber natürlich auch die Chance -, daß von deutscher Seite Fälle in die Kategorie „Mitläufer“ eingestuft wurden, die eben doch Zweifelsfälle waren, d. h. nach den Richtlinien der Militärregierung eigentlich in eine höhere Belastungsstufe gehörten. Da die Besatzungsmacht in den Fällen der Beamten, die neben ihrer politischen Belastung auch aus Altersgründen in den vorzeitigen Ruhestand versetzt worden waren, bereits Zugeständnisse gemacht hatte, war es nicht abwegig gewesen, die Haltung der Militärregierung als einen Teilrückzug von ihrer indiskutablen Einstufungsanordnung zu interpretieren. Obgleich weiterhin die Auffassung bestand, daß diese Richtlinien früher oder später ganz fallen müßten, beschloß das Kabinett jetzt, die Eingruppierung „nun einmal, wie abgesprochen, in Gang zu bringen“94. Die Angleichung der Künzel-Bescheide an die Belastungskategorien der Kontrollratsdirektive Nr. 38 sei umso dringlicher, bemerkte das Innenministerium in einer vertraulichen Notiz noch einmal, weil sonst die beruflichen Perspektiven der südwürttembergischen Angestellten und Beamten bei „einer etwa sich vollziehenden Vereinigung von Nord- und Südwürttemberg" gefährdet seien ${ }^{95}$. Offenbar verführt von dem Gedanken, die Besatzungsbehörde stehe derart unter Termindruck, daß sie über die stillschweigende Modifizierung ihrer Anweisungen hinwegsehen werde, begann der Staatskommissar die Einstufungen jetzt ,unter Zugrundelegung der von ihm und seiner Regierung der Militär-Regierung vorgeschlagenen Eingruppierungsordnung" ${ }^{\prime 96}$.

Doch damit hatte das Staatskommissariat den Bogen überspannt. In einem scharfen

93 Bericht Trabers an den Staatspräsidenten v. 25.11. 1947 über eine Besprechung bei der Milreg; SIG, Wü 13/514.

94 StaMiS 28.11. 1947.

95 Notiz v. 24. 12. 1947; SIG, Wü 42 P, acc. 10/70, A 13150.

96 Vergl. Trabers Anweisung für das Einstufungsverfahren v. 18. 11. 1947; SIG, Wü 13/514. 
Schreiben an Staatspräsident Bock stellte der Kabinettschef des Gouverneurs klar, aus den Zugeständnissen der Militärregierung bei der Eingruppierung älterer Beamter folge nicht, „daß ich meine Zustimmung zu Ihren allgemeinen Einstufungsvorschlägen gegeben hätte, deren Anwendung die Wirkung der Säuberungsmaßnahmen geradezu illusorisch machen würde". Die Nachprüfung der ersten 5000 vom Staatskommissar vorgelegten Fälle habe ergeben, daß die Richtlinien der Besatzungsbehörde mißachtet worden seien. Wenn sich die Landesregierung nicht an diese Vorschriften zu halten gedenke, dann werde sich der Säuberungsprozeß ,erheblich verzögern“97 im Klartext: dann würde die Militärregierung die Durchführung der Amnestie-Verordnung Nr. 133 blockieren.

Obgleich die Tübinger Militärregierung von Baden-Baden aus wohl gehalten war, angesichts des Integrationsprozesses der drei Westzonen einer Angleichung des Säuberungsprofils in Württemberg-Hohenzollern an das der Nachbarzone nichts mehr in den Weg zu legen, zeigte das Gouvernement Militaire in Tübingen Anfang 1948 noch keine Bereitschaft, die Konsequenzen der Einführung des Spruchkammerverfahrens in der französischen Zone und der veränderten politischen Großwetterlage zu akzeptieren. Der aufgrund übergeordneter politischer Entwicklungen nun verstärkt spürbare Zeitdruck verschärfte jetzt aber das prinzipiell nicht lösbare Dilemma der Tübinger Militärregierung, trotz der Einführung eines justizförmigen Entnazifizierungssystems auf der Beibehaltung von Säuberungsergebnissen zu beharren, die auf Entscheidungen in einem administrativen Entnazifizierungsverfahren zurückgingen. Ließ man zu, daß die Künzel-Bescheide unter dem Gesichtspunkt der Gleichbehandlung mit den Neufällen noch einmal durch die Spruchkammern liefen, dann würde das bisherige Säuberungsergebnis eingeebnet und die Entnazifizierung sich endlos hinziehen. Versuchte man, um in absehbarer Zeit zu einem Ende zu gelangen, die bereits entschiedenen Fälle durch einfachen Verwaltungsakt den Kriterien der Spruchkammergesetzgebung angleichen zu lassen, dann war das nur zu erreichen, wenn die Einstufungskriterien Ergebnisse ermöglichten, die nicht allzu weit von der allgemein bekannten und für die Betroffenen so günstigen Urteilsfindung der „Mitläuferfabriken“ in der Nachbarzone abwichen. Zu einer anderen Lösung konnte sich unter dem Druck der Öffentlichkeit keine deutsche Regierung - gleichgültig welcher parteipolitischen Ausrichtung - mehr bereit finden. Durch den zunehmenden Zeitdruck verschärfte sich dieses Dilemma. Es war nun im Wortsinne nur noch eine Frage der Zeit, bis die Sonderpolitik der Tübinger Militärregierung an ihren inneren Widersprüchen zerbrach.

Nach dem heftigen Zusammenprall mit der Landesregierung wegen der weiteren Behandlung der „Künzel-Bescheide“ wuchs bei der Militärregierung, die im Vorgehen des Staatskommissars einen Übertölpelungsversuch wittern mochte, noch einmal die Eskalationsbereitschaft. Als Druckmittel bediente sie sich der Amnestie-Verordnung. Hier stand die Landesregierung unter dem besonderen Druck der Öffentlichkeit, weil der Erlaß in Südbaden und Rheinland-Pfalz inzwischen zur Anwendung kam. Die dortigen Besatzungsbehörden hatten die Ausführungsbestimmungen zur Verordnung

${ }^{97}$ Schreiben v. 19. 1. 1948; SIG, Wü 13/456. 
Nr. $133^{98}$, die sie um die Jahreswende aus Baden-Baden erhalten haben dürften ${ }^{99}$, ziemlich bald an die deutschen Regierungen weitergegeben. Die Militärregierung in Württemberg-Hohenzollern dagegen machte nun die Amnestierung der großen Zahl der Bagatellfälle von der vorherigen Einstufung der alten Säuberungsurteile nach den Anweisungen der Militärregierung abhängig. Dieses unsinnige Junktim, das die Trennung zweier sachlich nicht zu trennender Komplexe zum Inhalt hatte, formulierte Gouverneur Widmer Anfang Februar 1948 gegenüber dem Staatspräsidenten Bock: „Die Durchführungsbestimmungen für die Verordnung 133 könnten von der Militärregierung nicht herausgegeben werden, ehe die Frage der Eingruppierung nicht klar gelöst sei“"100.

\section{Das Ende des südwürttembergischen Sonderweges in der politischen Säuberung}

Auf deutscher Seite stieß die Blockierung der Verordnung Nr. 133, die nebenbei bemerkt auch dem Ziel einer beschleunigten Entnazifizierung direkt zuwiderlief, auf einhellige Ablehnung. Nicht einmal Künzel selbst, der den Kurs der Tübinger Militärregierung am längsten befürwortete, mit eigenen Vorschlägen zum Modus der Einstufungen dann aber keine Resonanz mehr auf deutscher oder französischer Seite gefunden hatte ${ }^{101}$, unterstützte die Vorstellungen der Militärregierung zur Behandlung der Künzel-Bescheide. Der ehemalige Staatskommissar geriet zuletzt sogar in einen Gegensatz zur Besatzungsmacht, weil er sich weigerte, Säuberungsbescheide mit scharfen vermögensrechtlichen Konsequenzen gegen 19 Friedrichshafener Industrielle und Wirtschaftsmanager, die ihm von der Militärregierung diktiert worden waren, zu unterzeichnen und im Amtsblatt zu veröffentlichen ${ }^{102}$. Wie auch während seiner Amtszeit als Staatkommissar, so wollte er jetzt, wo die französische Demontageliste bekannt geworden war (Staatspräsident Bock: ein ,grausiges Hagelwetter“"103), erst recht alles vermeiden, was der Besatzungsmacht den Zugriff auf deutsche Industrieanlagen erleichtert hätte. Neben ihren säuberungspolitischen Implikationen wurde die Zurückweisung des dringenden deutschen Anliegens nach baldigem Beginn der Nominellen-Amnestierung von der Militärregierung vielleicht auch als Druckmittel in dem alles beherrschenden, wirtschaftspolitischen Dauerkonflikt mit der Landesregierung angesehen, der sich zu dieser Zeit zuzuspitzen begann. Nach überaus konfliktreichen

98 Vergl. die Erläuterungen des südbadischen SK v. 15. 1. 1948; SIG, Wü 13/444.

99 Vergl. das Schreiben des Justizministeriums von Rheinland-Pfalz an das Justizministerium in Tübingen v. 7. 1. 1948; StAL, Akten der LdJ, 2014'.

100 GouvS 6. 2. 1948.

101 Vergl. die Abschrift (29. 11. 1947) eines Schreibens von Künzel an die Milreg und den Staatspräsidenten (SIG, Wü 2, III, P 1016/3), seinen „Vorschlag zur Durchführung der Verordnung Nr.133“ v. 16.12.1947 (SIG, Wü 2, I, 610) sowie seinen Tätigkeits-Schlußbericht v. 18. 5. 1948; ebd.

102 Vergl. StaMiS 31. 10. 1947, 14.11. 1947, 2.1. 1948 sowie GouvS 26. 11. 1947.

103 Zit. nach Konstanzer, Entstehung, S. 66. 
Monaten entlud sich die Kontroverse um die „latente Reparationspolitik“104 der Franzosen Mitte 1948 in der spektakulären Vertagung des Landtages und dem Rücktritt der Regierung.

Die Militärregierung dürfte in ihrem Kurs, in Südwürttemberg eine von quasi-gerichtlichen Säuberungsgremien geprägte Entnazifizierung nicht hinzunehmen, auch durch die Ergebnisse bestärkt worden sein, die um die Jahreswende von den Spruchkammern des Internierungslagers in Balingen vorgelegt wurden ${ }^{105}$. Eine Prüfung ergab, daß die Kammern ihre Entscheidungen nicht nach politischen, sondern nur noch nach sozialen Gesichtspunkten fällten. In den ersten 40 Fällen, hatten die Spruchkammern die Betroffenen, größtenteils ehemalige Ortsgruppenleiter, durchwegs in die Gruppe der „Mitläufer“ oder „Minderbelasteten“ eingereiht, um sie vor einschneidenden Sühnemaßnahmen zu bewahren. Der Gouverneur verweigerte für beinahe die Hälfte der Urteile ${ }^{106}$ die Bestätigung der „falschen Einstufung als Minderbelastete statt als Belastete“107. Von der Auffassung, daß Ortsgruppenleiter grundsätzlich „Belastete“ seien, wich die Militärregierung unter Berufung auf die Kontrollrats-Direktive Nr. 38 zunächst auch nicht $\mathrm{ab}$, so daß es im Januar und Februar 1948 vorübergehend zu keinen weiteren Entlassungen aus dem Lager kommen konnte ${ }^{108}$. Auch hier war das Gouvernement Militaire, das im Verwaltungsverfahren Säuberungsurteile hatte beanstanden und ändern können, zunächst nicht bereit, sich mit den Konsequenzen der Einführung des Spruchkammersystems abzufinden und zu akzeptieren, daß in einem justizförmigen Verfahren die Entscheidungsfindung eben in quasi-richterlicher Unabhängigkeit vorgenommen wurde, die auch von einer mit uneingeschränkter Verfügungsgewalt ausgestatteten Militärregierung nicht durch Erwägungen politischer Opportunität zu korrigieren war. Staatskommissar Traber versäumte es nicht, die Besatzungsbehörde darauf hinzuweisen, daß ihr „Begehren“ nicht mit den geltenden Gesetzen vereinbar sei. Die Einstufung der Betroffenen hänge ausschließlich vom Ergebnis der Beweisaufnahme ab; anders vorzugehen sei nicht möglich: „Sonst verläßt man den Boden des Rechts und betritt den Boden des Unrechts, der Willkür“"109. Die Spruchkammern verfuhren in der Praxis freilich keineswegs nach dieser Maxime! Die Einstufungen wurden allein vom Strafmaß her vorgenommen. Die Kammern stuften einen Betroffenen nur deshalb nicht in die Gruppe der „Belasteten“ ein, weil sie diesem die damit verbundenen empfindlichen beruflichen Sanktionen ersparen

104 Ebd., S. 70. Zum Konflikt mit der Milreg ebd., S. 65-83.

${ }^{105}$ Das Internierungslager Balingen war am 1.9. 1947 von den Franzosen an die Abteilung XV des Innenministeriums übergeben worden. Die erste Lagerspruchkammer nahm ihre Tätigkeit am 14. 11. 1947, die zweite am 14.1. 1948 auf. Vergl. das Referat des Bevollmächtigten für das Internierungslager auf der Arbeitstagung des SK mit den KRUA-Vorsitzenden am 13.4. 1948 in Tübingen; SIG, Wü 13/26.

106 Nach einem Artikel der „Schwäbischen Zeitung“v. 16.1. 1948 hatte die Milreg von 59 Urteilen 24 nicht bestätigt.

107 Besprechung des deutschen Bevollmächtigten für das Lager Balingen mit der Milreg am 13. 1. 1948; SIG, Wü 2, I, 7161.

108 Referat des Bevollmächtigten am 13. 4. 1948; SIG, Wü 13/26.

109 Schreiben an die Milreg v. 17. 1. 1948; SIG, Wü 13/193. 
wollten, die „dem Internierten auch noch das Existenzminimum“ "nähmen. Falls die gesetzlich vorgeschriebene Sanktionsbestimmung für die Gruppe der „Belasteten“ allerdings, so der Vorsitzende der Lager-Spruchkammer an den Staatskommissar, in eine „Kann-Vorschrift" umgewandelt würde, „wären unsere Gewissenshemmungen gelöst". Geschähe das nicht oder bleibe die Militärregierung bei ihrer Haltung, sei die, faktische Selbstauflösung" der Kammern nicht aufzuhalten ${ }^{110}$. Daß die freie Beweiswürdigung der Kammern in der Praxis anders aussah als in der Darstellung Trabers gegenüber der Militärregierung, beeinträchtigt nicht die Durchschlagskraft seiner Argumente: Wollte oder konnte das Tübinger Gouvernement Militaire nicht den baldigen Zusammenbruch der politischen Säuberung in ihrem Besatzungsgebiet riskieren, blieb ihr nichts anderes übrig, als sich nach und nach von ihrem Sonderkurs zu lösen.

Bestanden durch die Restriktionen in Südwürttemberg bereits spürbare Unterschiede zu den übrigen Ländern der französischen Zone, so hatte sich durch das Festhalten der Tübinger Militärregierung an ihrem Sonderkurs eine tiefe Kluft zu der Entwicklung der Entnazifizierung in den anderen Zonen aufgetan, die von Regierung und Parteien mit wachsender Beunruhigung beobachtet wurde. In Südbaden und Rheinland-Pfalz war die Nominellen-Amnestierung in Gang, in der benachbarten US-Zone vollzog sich in der politischen Säuberung gerade ein „Rollentausch, wie es ihn sonst in der Besatzungsgeschichte kaum gegeben hat “111. Dort mußten sich die Deutschen jetzt dem überstürzten Rehabilitierungseifer der Amerikaner geradezu entgegenstemmen $^{112}$. In der sowjetisch besetzten Zone, wo die Nominellen schon im Sommer aus der politischen Säuberung entlassen worden waren, hatte die Militäradministration die Entnazifizierung am 26.2.1948 für beendet erklärt und die Säuberungsorgane aufgelöst. Unter diesen Umständen war es kein Wunder, daß „Unwillen und Verbitterung "113 um sich griffen. Die Appelle an das Gouvernement Militaire in Tübingen, die Zeichen der Zeit nicht zu ignorieren, wurden nun drängender; die Parteien übertrafen einander an Einsatz für die Gruppe, die zur Amnestierung anstand, immerhin über 10 Prozent der wahlberechtigten Bevölkerung. Der sonst kaum in Erscheinung getretene „Politische Beirat beim Staatskommissar" entfaltete hier vorübergehend einige Aktivität.

Nach dem Säuberungsgesetz war der Politische Beirat, dem je ein Parteienvertreter angehörte, eigentlich „ein nahezu dem Staatskommissar gleichgeordnetes Organ“"114. Er war zur Einsicht der Akten befugt, konnte kritische Anmerkungen zur Arbeit der Säuberungsorgane machen und hatte das Recht, von sich aus Revision gegen Entnazifizierungsbescheide einzulegen. Doch in der Praxis fanden die nebenamtlich tätigen Beiräte keine Möglichkeit, ihre Rechte auszuschöpfen oder sich systematisch und in größerem Stil in einzelne Fälle zu vertiefen; sie blieben von der Informations- und Kooperationsbereitschaft des Staatskommissars abhängig. Einige Male hatte der Bei-

110 Zitate im Schreiben v. 16. 1. 1948; SIG, Wü 13/193.

111 Gimbel, Amerikanische Besatzungspolitik, S. 228.

112 Vergl. Niethammer, Entnazifizierung, S. 512. Zur sowjetischen Besatzungszone, ebd., S. 509, 514.

113 Schreiben Trabers an die Milreg in Baden-Baden v. 18. 5. 1948, Anlage 9; SIG, Wü 13/456.

114 Schreiben des SPD-Vertreters im Politischen Beirat an den SK v. 28. 8. 1947; SIG, Wü 13/224. 
rat vergebens eine bessere Unterrichtung und dann sogar regelmäßige Berichte vom Säuberungskommissar gefordert ${ }^{115}$. Doch Traber, der den unmittelbaren Kontakt zu den Spitzen der drei Regierungsparteien vorzog und im übrigen meinte, der Beirat solle sich „,selbst um die Ausübung seiner Rechte kümmern", 116 fand erst ein halbes Jahr nach Antritt seines Amtes Zeit zu einer ersten gemeinsamen Sitzung ${ }^{117}$. Eine kurze Blüte entfaltete das Gremium mit einem Vorstoß beim Gouvernement Militaire, in dem die deutsche Argumentation noch einmal zusammengefaßt war. Wie alle an dem Prozeß der Entnazifizierung Beteiligten waren sich auch die vier Mitglieder des Beirats darüber einig, daß die zufriedenstellende Regelung der Amnestierung und Eingruppierungen „,die wichtigsten Probleme bei der Entnazifizierung darstellen“"118. Die Parteienvertreter wiesen die Militärregierung auf die,,in der Bevölkerung befindliche Spannung und Unruhe hin" und forderten sie auf, endlich das von ihr konstruierte Junktim aufzugeben ${ }^{119}$. Doch ihre, ,als Ausdruck des Willens der politischen Parteien “ vorgetragene Resolution ${ }^{120}$ hinterließ bei der Besatzungsbehörde auch nicht mehr Eindruck als die ständigen Anläufe des Staatskommissars. Den Leiter der Säuberungsabteilung wird der Beirat mit seiner vorsichtigen Anfrage, ob sich die Militärregierung mit der Veröffentlichung der vom Beirat vorgelegten Resolution einverstanden erklären könne, nicht eben von seinem politischen Schwergewicht und seiner Durchschlagskraft überzeugt haben. Die Erlaubnis zur Publikation ließ auf sich warten, der deutsche Vorstoß verlief ergebnislos. Dieser Mißerfolg ließ den zur CDU gehörigen stellvertretenden Vorsitzenden des Beirats resignieren. Er begründete seinen Rücktritt damit, daß die Militärregierung trotz ,aller Vorschläge und Einwendungen sowie Hinweise auf die öffentliche Meinung im In- und Ausland" auch nach der Intervention des Politischen Beirats nicht von ihrem Junktim, ,das in keiner Weise Berechtigung haben kann", abrücken wollte ${ }^{121}$. Noch wirkungsloser blieb die Große Anfrage der DVP-Fraktion im Landtag, weshalb in Württemberg-Hohenzollern im Gegensatz zu den anderen Ländern der französischen Zone die Ausführungsbestimmungen zur Verordnung Nr. 133 noch nicht erschienen seien ${ }^{122}$. Sie wurde ein halbes Jahr lang nicht einmal auf die Tagesordnung gesetzt. Zuerst, weil die Kommunikationsbereitschaft der Militärregierung in puncto Diskussionsrechte des Landtags bereits in der Demontage-Frage aufs äußerste belastet war ${ }^{123}$, später wurde die Debatte

115 Vergl. die Schreiben des Politischen Beirats v. 28. 8. 1947, 22.9. 1947 (beide in SIG, Wü 13/224) und v. 16. 12. 1947 (SIG, Wü 13/202).

116 Notiz Trabers für ein Treffen mit dem südbadischen SK in Freiburg am 3. 11. 1947; SIG, Wü 13/ 523.

117 Vergl. das Protokoll der Sitzung am 8. 1. 1948; SIG, Wü 13/226.

118 Protokoll über die außerordentliche Sitzung des Politischen Beirats am 31. 1. 1948; SIG, Wü 13/ 37.

119 Bericht des Politischen Beirats über die Verhandlungen mit der Milreg am 1. 3. 1948; SIG, Wü $13 / 225$.

120 Protokoll der Sitzung des Politischen Beirats am 20. 1. 1948; die Resolution in der Anlage; ebd.

121 Schreiben an die Landesleitung der CDU v. 31. 3. 1948; SIG, Wü 13/37.

122 Große Anfrage v. 3. 2. 1948; Landtag von Württemberg-Hohenzollern - Beilage 82.

123 Vergl. Konstanzer, Entstehung, S. 65 ff. 
verschoben, weil ,die Verhandlungen mit der Militärregierung wegen der Anwendung der VO 133 in das kritische Stadium eingetreten" waren ${ }^{124}$. Auch ein Versuch Trabers, den Druck der Öffentlichkeit auf die Militärregierung durch einen Zeitungs$\operatorname{artikel}^{125}$ zu mobilisieren, in dem er den Verantwortlichen für das Ausbleiben der Nominellen-Amnestie zwischen den Zeilen zu nennen versuchte, konnte die Besatzungsmacht nicht recht beeindrucken.

Einige taktische Zugeständnisse konnten nicht darüber hinwegtäuschen, daß sich an der Strategie der Délégation Supérieure in Tübingen bis zum Sommer 1948 nichts änderte. Deutlich zurückstecken mußte die Besatzungsmacht nur gegenüber dem Unabhängigkeitsanspruch der Spruchkammer im Internierungslager Balingen, weil sie nicht riskieren konnte, daß die übrigen Kammern ihre Tätigkeit aus Solidarität ebenfalls zu reduzieren begannen. Der Gouverneur rückte deshalb nach und nach von seiner Forderung ab, ,wonach ein Ortsgruppenleiter grundsätzlich als Belasteter an-

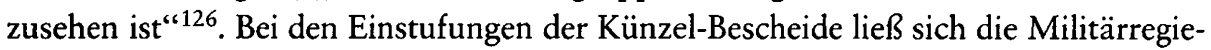
rung zu geringfügigen Konzessionen herbei, bestand im übrigen aber weiterhin auf der Anwendung ihrer Richtlinien ${ }^{127}$. So beschränkten sich die Eingruppierungen nur auf Fälle, die nach beiderseitiger Auffassung zweifelsfrei zur Kategorie der „Mitläufer“ zählten. Zwar konnten bis zum April zwar ca. 20000 Säuberungsbescheide eingestuft werden, doch das Gouvernement Militaire bestand darauf, daß ein außerordentlich hoher Sockel, nämlich mehr als 10 Prozent der Betroffenen, in eine der ersten drei Belastungskategorien zu fallen hatten ${ }^{128}$. Daß ein solches Profil im Frühjahr 1948 ein ganz ungewöhnliches Resultat der politischen Säuberung war, wird deutlich, wenn man sich vor Augen hält, daß in der Schlußbilanz der Entnazifizierung in Württemberg-Hohenzollern - nach Ablauf der Bewährungsfrist von zwei Jahren für die „,Minderbelasteten " - weniger als ein Viertel Prozent aller Betroffenen in die Gruppen I bis III des Säuberungsgesetzes fielen ${ }^{129}$. Die Appelle der deutschen Seite, die Richtlinien endlich fallen zu lassen, wurden vom Gouvernement Militaire jedesmal mit dem Hinweis auf die „,kategorisch“ ablehnende Haltung Baden-Badens zurückgewiesen ${ }^{130}$. Es hat den Anschein, als sei dies lange Zeit tatsächlich der Fall gewesen, da auch die anderen Länder der französischen Zone in ähnliche Kontroversen mit der Besatzungsmacht verwickelt waren ${ }^{131}$. In Südbaden ruhten die Eingruppierungsarbeiten ganz ${ }^{132}$.

124 Schreiben des SK an die Staatskanzlei v. 30.6. 1948; SIG, Wü 13/444.

125 „Die Entnazifizierung in Süd-Württemberg“. Beitrag des SK in der „Schwarzwälder Post“ Nr. 6/ 1948.

126 Referat des Bevollmächtigten für das Internierungslager Balingen auf einer Arbeitstagung der südwürttembergischen Säuberungsorgane am 13.4.1948; SIG, Wü 13/26.

127 Schreiben der Milreg an den Staatspräsidenten v. 27. 2. 1948; SIG, Wü 2, III, P 1016/1.

128 Tätigkeitsbericht des SK für das 1. Quartal 1948 v. 15.4.1948; danach hatte die Milreg von 21469 Einstufungen allein aus dem Bereich des öffentlichen Dienstes 2353 Fälle zurückgewiesen; SIG, Wü $13 / 35$.

129 Vermerk der Abwicklungsstelle für die politische Säuberung v. 18. 4. 1952; SIG, Wü 13/21.

130 GouvS 12. 2. 1948; vergl. auch StaMiS 13.2.1948.

131 StaMiS 13. 2. 1948.

132 Entwurf Trabers für einen Zeitungsbeitrag, wohl von Februar 1948; SIG, Wü 13/25. 
Instrument des genuinen Blockadekurses der Tübinger Militärregierung war es allerdings, diese Form der Einstufung der Künzel-Bescheide durch die „widerrechtliche“ (Traber) Blockierung der Nominellen-Amnestie erzwingen zu wollen. Dieses Junktim bestand weder in Südbaden noch in Rheinland-Pfalz, denn dort wurde die Verordnung Nr. 133 ungeachtet der Kontroverse um die Eingruppierung der früheren Säuberungsurteile durchgeführt ${ }^{133}$.

Es dauerte bis Ende Mai 1948 - in London tagte zu dieser Zeit die Sechs-MächteKonferenz in ihrer zweiten Sitzungsperiode, in Berlin war der Alliierte Kontrollrat nach dem Auszug des sowjetischen Vertreters zusammengebrochen - bis sich die Landesregierung entgegen den Warnungen der Tübinger Besatzungsbehörde, „ein Vorstoß in Baden-Baden durch Staatskommissar Traber werde ohne jeden Zweifel erfolglos bleiben“"134, zu einem Ausbruch aus dem „circulus vitiosus“ dieses Junktims entschloß. Eingeleitet wurde der Schritt mit einer 25-seitigen Denkschrift Trabers an das französische "Gouvernement de la Zone Française d'Occupation“135, in der er noch einmal alle Einwände der Landesregierung gegen den Tübinger Sonderkurs Revue passieren ließ. Der Bedeutung des Adressaten und des Vorstoßes angemessen ließ er sich eine entsprechend überhöhte Argumentation angelegen sein. Zwar könne es keinen Zweifel geben, so Traber, daß sich die Deutschen wegen der „Ungeheuerlichkeiten und der Schäden, die der Nationalsozialismus dem deutschen Volke und erst recht den Allierten angetan hat" ihrer Wiedergutmachungspflicht ,vor der Geschichte nicht entziehen dürften ". Doch seit Kriegsende habe sich, was die Entnazifizierung angehe, nach und nach ein großer Stimmungsumschwung vollzogen. In den anderen Zonen sei die politische Säuberung inzwischen sogar schon abgeschlossen. Nur in Württemberg-Hohenzollern seien ,noch tausende tüchtigster Arbeitskräfte von der Teilnahme am Wiederaufbau durch die Unentschiedenheit ihrer politischen Zuverlässigkeit ausgeschlossen“. In Anbetracht dieser Lage und allein schon „im Interesse der Rechtsgleichheit innerhalb der französischen Zone" sei es geboten, endlich auch in Württemberg-Hohenzollern die Verordnung Nr. 133 anzuwenden und die Eingruppierungsrichtlinien zu ändern. Wenn das „künftige Verhältnis zwischen uns und dem großen französischen Volk" nicht bleibenden Schaden haben solle, so schrieb der Staatskommissar, dann sei die Entnazifizierung, ebenso wie in den anderen Zonen auch, jetzt rasch zu beenden. Könnten sich die Franzosen nicht zu diesem Schritt verstehen, so sei ,damit eine sich nicht wiederholende historische Gelegenheit zur Völkerversöhnung zum Schaden der Völker für immer verpaßt". Eine Woche danach, am 28. 5. 1948, fuhr Traber zu zwei Besprechungen nach Baden-Baden. Was dem Staatskommissar in Baden-Baden vom Leiter der Entnazifizierungs-Abteilung und vom Chef der Innen- und Kultusverwaltung der zentralen Militärregierung gesagt wurde, war nichts weniger als eine politische Sensation. In allen Fragen der Entnazifizierungspolitik, um die er mit der Tübinger Délégation Supérieure ein

\footnotetext{
133 Tätigkeitsbericht des SK für das 1. Quartal 1948 v. 15.4. 1948; SIG, Wü 13/35.

134 GouvS 12. 2. 1948.

135 Schreiben Trabers an die Milreg in Baden-Baden v. 18. 5. 1948; SIG, Wü 13/456.
} 
Jahr lang gerungen hatte, fand Traber die Vertreter der Militärregierung auf seiner Seite ${ }^{136}$.

Nach den Aufzeichnungen des Staatskommissars zeigte man in Baden-Baden „,vollstes Verständnis" dafür, daß er sein Amt ,nach den mit der Militärregierung in Tübingen gemachten Erfahrungen" nur noch weiterführen wolle, wenn er seine Befugnisse aus der Rechtsanordnung künftig uneingeschränkt wahrnehmen könne. Die Vertreter der zentralen Besatzungsbehörde zeigten sich ,erstaunt", als sie erfuhren, daß sich die Militärregierung in Tübingen sämtliche Revisionsanträge, insbesondere die gesetzlich garantierten, zur Genehmigung vorlegen lasse: „Beide Herren erklärten dieses Verlangen für untragbar." Ferner wurde Traber erklärt, daß die von der regionalen Militärregierung verlangte Eingruppierung ,unmöglich sei.“ Zugleich wurde ihm zugesagt, daß die Scheidelinie zwischen der Gruppe der „Mitläufer" und den Gruppen I bis III so verlaufen könne, wie es von deutscher Seite als angemessen empfunden würde. Am nachhaltigsten verblüfft haben dürfte die deutsche Delegation allerdings, was sie von den französischen Besatzungsoffizieren zu der Blockierung der Nominellen-Amnestie erfuhren: „In Baden-Baden wußte man nichts davon und war darüber erstaunt, daß die VO 133 in unserem Lande nicht angewendet werde." Verständlich, daß der Staatskommissar seine Uberraschung nicht verbergen konnte und zu seinen Gesprächspartnern sagte, es sei ihm unverständlich, daß ,der Zonenbefehlshaber zu einem ganz bestimmten Zweck (Beschleunigung des Verfahrens) eine Verordnung erlasse und eine Provinzialregierung eigenmächtig bestimme, ob die Verordnung bei ihr durchgeführt werde oder nicht". Abschließend konnte er die Zusage mit nach Tübingen nehmen, daß in der französischen Zone schon bald eine Amnestie erlassen werde, unter die generell alle „Mitläufer“ fallen sollten, gleichgültig ob sie „Amt oder Titel" gehabt hatten. Die Aussichten für eine baldige Liquidierung der Entnazifizierung in Württemberg-Hohenzollern nach deutschen Vorstellungen waren jetzt mehr als nur ,günstig“, wie Traber resümierend zum Schluß seines Berichts meinte. Die Landesregierung stand - wie schon so oft - vor einer völlig neuen Lage.

Die Quellenlage läßt gegenwärtig nur Spekulationen darüber zu, wie weit die Zentrale in Baden-Baden vom Sonderkurs des Gouvernement Militaire in Tübingen unterrichtet war. Es ist nicht ausgeschlossen, daß sie doch bessere Kenntnis von der eigenwilligen Säuberungspolitik der Militärregierung in Südwürttemberg hatte, als sie jetzt gegenüber dem Staatskommissar zuzugeben bereit war. Der Vorstoß Trabers fiel mitten in die Umorientierungsphase der französischen Besatzungspolitik; es ist gut möglich, daß die Militärregierung in Baden-Baden über den Kurs des Gouverneurs in Württemberg-Hohenzollern wenige Wochen zuvor noch anders dachte, sich inzwischen aber ein wenig Generosität gegenüber den Besuchern aus Südwürttemberg leisten konnte. Gleichwohl ist es bei der weitgehenden Unabhängigkeit der regionalen Delegationen, die, wie die Untersuchungskommission der Nationalversammlung kri-

136 Aufzeichnung Trabers über die Besprechung bei der Milreg in Baden-Baden am 28. 5. 1948, 9.30 Uhr - 12.30 Uhr und 15.30 Uhr - 17.30 Uhr; SIG, Wü 13/55. Vergl. auch den Bericht des Freudenstädter Amtsgerichtsrats, Trabers Freund und Dolmetscher, über den Empfang des SK durch den Chef der Innen- und Kultusverwaltung der Milreg am gleichen Tag; ebd. 
tisiert hatte, manchmal handelten, als ob eine übergeordnete Autorität gar nicht existiere $^{137}$, ebenso gut möglich, daß in Tübingen von der Militärregierung in der Entnazifizierung eine Sonderpolitik ganz nach eigenen Vorstellungen getrieben worden war. Daß dort vom Gouvernement Militaire nicht selten eigene Wege eingeschlagen worden sind, berichtet jedenfalls René Cheval, seinerzeit verantwortlich für Angelegenheiten der Universität Tübingen. Anordnungen aus Baden-Baden seien, wenn sie sich nicht ins eigene Konzept fügen ließen, schon hin und wieder ,,wegen des besonderen Volkscharakters der Schwaben " für undurchführbar ausgegeben worden ${ }^{138}$. Gleichermaßen fällt es schwer, ein verläßliches Bild der maßgeblichen Kräfte innerhalb der französischen Besatzungsbehörden in Baden-Baden und Tübingen zu skizzieren, zu bestimmen, welche Kräfte mit welchen politischen Vorstellungen im einzelnen in Tübingen etwa zur Gruppe der „Anti-Revisionisten“ zu zählen sind. Es bedarf des Zugangs zu den französischen Besatzungsakten, um zu klären, ob der Tübinger Sonderkurs eher von dem Bestreben diktiert war, eine organisatorisch gut einsetzbare Entnazifizierungs-Bilanz nicht zu verlieren oder ob - wenigstens bei einzelnen - hinter der dort verfochtenen harten Linie ein bestimmtes Bild vom Nationalsozialismus und der sozialen Teilnahme an ihm bestanden hat. Unabhängig von der Klärung solcher Fragen bleibt die Feststellung, daß der Sonderkurs der Militärregierung für Württemberg-Hohenzollern in der Entnazifizierungspolitik erst im Sog der Integrierung der französischen Zone in den Prozeß der Weststaatsgründung sein Ende gefunden hat: Die den Ländern der französischen Zone zugestandene Erweiterung ihrer Kompetenzen ${ }^{139}$ Ende Juli 1948 fiel beinahe auf den Tag genau mit dem Erlaß der Verordnung Nr. $165^{140}$, der Amnestierung aller „Mitläufer“, und der neuen Säuberungsrichtlinien in Südwürttemberg zusammen, die nun der umfassenden und endgültigen Liquidierung der Entnazifizierung nichts mehr in den Weg legten.

\section{Verfall und Angleichung der Entnazifizierung an die Maßstäbe in der amerikanischen Besatzungszone}

Der nach mehr als dreijähriger Besetzung schon eigene Traditionen ausbildenden Gewohnheit der französischen Besatzungsmacht, Kurswechsel in der Entnazifizierung aus anderen als säuberungspolitischen Erwägungen heraus vorzunehmen, mußte sich Mitte 1948 auch die Délégation Supérieure in Tübingen beugen. Der Effekt war bemerkenswert: Die Militärregierung in Südwürttemberg hatte die Schlacht gewonnen, aber den Krieg verloren; sie hatte sich in den Auseinandersetzungen um ihren

137 Assemblée, Documents, Annexe Nr. 959.

138 Mündliche Information. Zu Chéval vergl. Carlo Schmid, Erinnerungen, S. 260.

139 Schreiben General Koenigs an die Gouverneure der Länder (Nr. 03936/CC/CAC/POL - Geheim-) v. 15. 7. 1948; SIG, Wü 2, II, 8008. Zur Kenntnis der Landesregierung gelangte der Inhalt dieses Schreibens durch den Brief von Gouverneur Widmer an den Staatspräsidenten v. 28. 7. 1948; SIG, Wü 2, I, 100. Vergl. Konstanzer, Entstehung, S. 79.

140 VO Nr. 165 v. 13. 7. 1948; J.O., S. 1588. Die Ausführungsbestimmungen hierzu und die zukünftige Regelung der Entnazifizierung in Württemberg-Hohenzollern enthält das Schreiben des Gouverneurs an den SK v. 27. 7. 1948; SIG, Wü 2, II, 6800/5. 
säuberungspolitischen Sonderkurs gegen die Landesregierung praktisch uneingeschränkt durchsetzen können, mußte aber nun erleben, wie der Dammbruch in der Entnazifizierung alle Schranken fortspülte, die von ihr im Laufe eines Jahres gegen den deutschen Rehabilitierungselan aufgerichtet worden waren. Zwar hatte sich die abenteuerliche Konstruktion der Militärregierung, die Entnazifizierung vor der Fassade der Spruchkammergesetzgebung de facto nach dem alten Verwaltungsverfahren zu Ende zu bringen, gleich zu Beginn als nicht tragfähig erwiesen, das Hauptziel der Militärregierung in Württemberg-Hohenzollern, die Säuberung der Ära Künzel gegen alle Revisionsbestrebungen $z \mathfrak{u}$ verteidigen, hatte sie aber für etwa ein Jahr zweifellos erreicht. Trotz einer Gesetzgebung mit weitreichenden Revisionsgarantien für die Betroffenen und den Säuberungskommissar, trotz des Zusammenbruchs der politischen Säuberung in den übrigen Besatzungszonen und trotz einer inzwischen entnazifizierungsmüden, ja entnazifizierungsfeindlich gewordenen Öffentlichkeit, hatte sie die Konservierung der zum Teil einschneidenden Ergebnisse eines Anfang 1946 konzipierten und nach den zu dieser Zeit gültigen Maßstäben stringent durchgeführten Verfahrens durchgesetzt. Die Bilanz, ein Jahr nach Inkrafttreten des Spruchkammergesetzes, mit dem die Landesregierung die Ergebnisse der Ära Künzel zu bereinigen gedachte, bestand in vierzehn rechtskräftig aufgehobenen Säuberungsentscheiden schwereren Kalibers ${ }^{141}$; das hieß: an der Struktur der Resultate des Verwaltungsverfahrens hatte sich nichts geändert. Um das zu erreichen, hatte das Gouvernement Militaire die beiden Wege, die zur Einebnung des alten Säuberungsprofils führten, nämlich die Eingruppierung der Künzel-Bescheide nach den Kriterien der Spruchkammergesetzgebung und die Revisionsmöglichkeiten, versperrt. Innerhalb des einen Jahres waren zwar etwa zwei Drittel der Urteile aus dem Verwaltungsverfahren neu eingruppiert worden ${ }^{142}$. Doch infolge der scharfen Richtlinien der Militärregierung, die noch mit der Aussetzung der Nominellen-Amnestie gekoppelt waren, handelte es sich dabei nur um Bagatellfälle, bei denen weder in der Landesregierung noch in der Militärregierung Zweifel darüber bestanden, daß sie nicht in die Gruppe wirklich schwer Belasteter (,Hauptschuldige“, „Belastete“) gehörten. Die von Künzel mit Berufsverbot, Entlassung oder hohen Geldbußen Belegten konnten hier nicht durchrutschen. Den anderen Weg, das Recht auf Revision der Künzel-Bescheide, hatte die Militärregierung ebenfalls unter Kontrolle, denn sie behielt sich generell deren Genehmigung vor. Die Befugnisse des Säuberungskommissars, Revision bei Betroffenen

${ }^{141}$ Bis zum 30.6. 1948 sind jeweils in der Beilage 12, S. 120, Beilage 14, S. 128 und der Beilage 15, S. 132 des Regierungsblattes für das Land Württemberg-Hohenzollern, Jahrgang 1948, die insgesamt 14 Revisionsentscheidungen veröffentlicht. Darin wurden 5 Betroffene als, Mitläufer', 9 als ,Minderbelastete' eingestuft. Bearbeitet, aber von der Militärregierung noch nicht genehmigt, waren bis dahin insgesamt 720 Revisionsanträge. Tätigkeitsbericht des SK für das 2. Quartal 1948 v. 20.7. 1948; SIG, Wü 13/35.

142 Eingruppiert waren bis Ende Juni 1948 rund 56000 von den etwa 80000 Künzel-Bescheiden. Davon hatte die Milreg in 10000 ihre Zustimmung versagt; ebd. Veröffentlicht waren bis dato 1800 Einstufungen. Praktisch alle fielen unter ,Nicht Betroffen', ,Unbelastet', ,Mitläufer' u. ä. Nur 7 Einstufungen lauteten auf ,Minderbelasteter', keine auf ,Hauptschuldiger' oder ,Belasteter'; vergl. Beilage 13 des Regierungsblattes, Jahrgang 1948, v. 13.6. 1948. 
einzulegen, die eigentlich keinen gesetzlichen Anspruch darauf hatten - in dieser Befugnis hatte die deutsche Seite bei Annahme des Gesetzes das Instrument zu einer Generalrevision erblickt -, war, zur Empörung der Landesregierung vom Gouverneur von Anfang an blockiert worden. Traber wurde dennoch nicht müde zu betonen, er sei ,grundsätzlich bereit, in allen Fällen, in denen der Betroffene sich beschwert fühlt, seinerseits die Revision zuzulassen"143. Hier konnte die Militärregierung mit dem Hinweis auf Geist und Wortlaut der Präambel, aus der sich nicht ohne weiteres ein regelmäßig zugunsten des Betroffenen ausfallendes Revisionsrecht des Staatskommissars ableiten ließ, den klaren Bruch ihrer Zusagen während der Verhandlungen um Annahme des Gesetzes noch leidlich zu rechtfertigen versuchen. Sogar der Weg einer Einschränkung des Revisionsrechts, das allen mit schweren Sanktionen Belegten gesetzlich garantiert war, wurde von der Besatzungsmacht anfangs beschritten - ein direkter Affront des Gouverneurs gegen gesetzliche Normen und die Grundlagen der Rechtssicherheit überhaupt. Immer wieder hatte die Militärregierung auch solche Revisionssachen „teils zurïckgestellt“ ${ }^{\text {144 }}$. An dieser schwächsten Stelle ihrer Strategie der Rehabilitierungs-Blockade waren die Franzosen zwar allmählich von dem Standpunkt abgerückt, daß,,sie auch diejenigen Revisionen, die aufgrund eines gesetzlichen Anspruchs vom Betroffenen eingelegt worden seien, nicht zulassen" könnten ${ }^{145}$. Es dauerte aber sogar hier bis zu dem Umschwung in der Entnazifizierung im Sommer, ehe „die Behandlung dieser Sachen bis auf etwa 40 Fälle, in denen eine erhebliche Belastung der Betroffenen vorliegen soll, freigegeben“" wurde ${ }^{146}$. Da die Revidierung der alten Säuberungsurteile für die deutsche Seite absolute Priorität hatte - die Säuberungsgremien waren wiederholt in diesem Sinne angewiesen worden -, wandten sich die Spruchkammern Neufällen in der Regel nur dann zu, wenn im Augenblick keine Revisionsfälle zur Verhandlung vorlagen. Deswegen waren die Kammern in dieser Nebentätigkeit auch nicht sehr erfolgreich. Hier wurden vor allem jene Fälle behandelt, die Künzel nach seinem Rücktritt nicht mehr hatte entscheiden können (noch „längstens sechs Wochen“ Arbeit, wie Künzel seinerzeit gemeint hatte ${ }^{147}$ ). Von diesem Restbestand war Ende Juni 1948 zwischen einem Drittel und der Hälfte bearbeitet $^{148}$. Die Masse von diesen Urteilen hatte die Militärregierung allerdings noch nicht genehmigt, so daß ein Jahr nach Inkrafttreten des Spruchkammergesetzes erst ganze 731 Säuberungsurteile erster Instanz Rechtskraft erlangt hatten ${ }^{149}$.

143 Dienstbesprechung im Staatskommissariat am 20.2.1948; SIG, Wü 13/36. Vergl. auch das Interview des SK in der „Schwäbischen Zeitung“ v. 3.10. 1947.

144 Tätigkeitsbericht des SK für das 2. Quartal 1948 v. 20.7. 1948; SIG, Wü 13/35.

145 Besprechung des Politischen Beirats mit dem SK am 8. 1. 1948; SIG, Wü 13/226.

146 Wie Anm. 144. 147 Tätigkeits-Schlußbericht Künzels v. 18. 5. 1948; SIG, Wü 2, I, 610.

${ }^{148}$ Die Angaben über die Zahl der von Künzel auf den neuen Staatskommissar übergegangenen erstinstanzlichen Restfälle schwanken. Künzel gibt die Zahl 6065 an (wie Anm. 147), Traber spricht von 10-12000 Fällen (Zeitungsartikel in der „Schwarzwälder Post“, Nr. 6/1948). Die Spruchkammern hatten bis Ende Juni 19483000 Neufälle verhandelt, von denen die Milreg aber erst 1000 Entscheidungen genehmigt hatte; Tätigkeitsbericht des SK für das 2. Quartal $1948 \mathrm{v}$. 20. 7. 1948; SIG, Wü 13/35.

149 Vergl. die Beilagen 12, 14 und 15 des Regierungsblattes, Jahrgang 1948. 
So dürftig die Zahl der vorgelegten Säuberungsurteile auch war, ihr Tenor erregte sogleich allgemeines Aufsehen. Außer den Betroffenen war niemand mit den vorgelegten Resultaten einverstanden. Sogar dem Staatskommissar bereiteten sie „erhebliche Sorge“, denn die gefällten Entscheidungen waren nach seiner Auffassung ,in vielen Fällen erheblich zu mild" und entsprächen nicht dem, was man billigerweise erwarten könne. Nicht nur die früher Entnazifizierten, so meinte er gegenüber den Vorsitzenden der Kammern, seien „darüber beunruhigt und bestürzt“, auch die Offentlichkeit reagiere zum Teil „mit Empörung und Entrüstung“. Er habe sich sogar veranlaßt gesehen, einen abwiegelnden Zeitungsartike ${ }^{150} \mathrm{zu}$ schreiben, um die aufwallende öffentliche Meinung zu kanalisieren. Eindringlich forderte er die Vorsitzenden auf, daß „mit dieser unerfreulichen Rechtsprechung ein Ende gemacht werden müsse“151. In anderem Zusammenhang verwies er auf einen Fall, den er zufällig selbst „ganz genau“ kenne, dessen Einstufung als „Mitläufer“ durch die Spruchkammern „der Wirklichkeit Hohn spricht ${ }^{\text {"152 }}$. Die Ermittlungsinstanz in der südwürttembergischen Version des Spruchkammersystems, die Kreisuntersuchungsausschüsse, hätten den Betroffenen dagegen realitätsgerecht ohne Bezüge entlassen wollen. Dies war kein Einzelfall. Als die Entscheidungen nach und nach bekannt wurden, wurde von dieser Seite die heftigste Urteilsschelte geübt. Bemerkenswert ist dies auch deshalb als einer der Hauptkritikpunkte, den die Gegner des Verwaltungsverfahrens vorgebracht hatten, ja die Abweichung Künzels von den Sanktionsvorschlägen der Untersuchungsausschüsse in den Kreisen gewesen war. Die Argumente der KRUAS kehrten jetzt wieder und Traber erhob sie nun selbst. Der Tuttlinger Ausschuß beispielsweise drohte mit seinem Rücktritt, falls die Praxis der Spruchkammern sich nicht ändern sollte. Anhand von einzelnen Beispielen demonstrierte der KRUA in seinem Schreiben an den Staatskommissar ${ }^{153}$, daß sich die Spruchkammern in Tübingen ohne Rücksprache über die Bewertung des Betroffenen durch den Ausschuß hinweggesetzt hätten. Der Säuberungskommissar wurde aufgefordert, zu ermitteln, wie es zu solchen Entscheidungen habe kommen können. Für alle KRUAS ergab sich aus dieser Diskrepanz der Beurteilung nämlich eine schwere Belastung in ihrem Landkreis, der die meisten - je länger je weniger - standzuhalten vermochten. Die „fortgesetzte Milderung“ der Sanktionsvorschläge der Kreisgremien durch die Spruchkammern, die jeden Einzelfall fraglos am besten beurteilen konnten, war ein empfindlicher Schlag für das ganze Säuberungsverfahren. Denn für die Bevölkerung am Ort wurde die Entnazifizierung von den Ausschüssen und nicht von den in Tübingen ansässigen Spruchkammern repräsentiert. Für die Mitglieder wurde es zunehmend schwieriger ihr Ansehen zu wahren, der ganze Ausschuß, so auch Traber, müsse sich höchst ,überflüssig vorkommen und lächerlich gemacht vor der Öffentlichkeit“". Der „Haß“ der nun Entlasteten

150 Vergl. Trabers Beitrag „Veränderte Rechtsprechung in der Entnazifizierung“ in der Zeitung „Der Württemberger“" v. 22.5. 1948.

151 Protokoll einer Dienstbesprechung des SK mit den Spruchkammervorsitzenden am 21. 5. 1948; SIG, Wü 2, I, 610.

152 Schreiben des SK an die Spruchkammervorsitzenden v. 12. 5. 1948; SIG, Wü 13/116.

153 Schreiben v. 7. 5. 1948; SIG, Wü 13/116. 
auf die Untersuchungsausschüsse würde in gefährlicher Weise geschürt: ,Ihr hättet uns erheblich geschädigt", so höre man nun von den Entlasteten, berichtete der Säuberungskommissar den Spruchkammervorsitzenden über die Stimmung an einigen Orten, „wenn die Spruchkammern in Tübingen nicht vernünftig gewesen wären; das werden wir uns merken". Tatsächlich seien in letzter Zeit Mitglieder des Kreisuntersuchungsausschusses Biberach von Betroffenen in gröbster Weise beschimpft und belästigt worden ${ }^{154}$. Durch das Land ging schon bald das geflügelte Wort: „Als große Nazi fahren sie nach Tübingen und als kleine kommen sie heim" ${ }^{155}$. Wesentlichster Grund der Diskrepanzen zwischen Spruchkammern und Kreisausschüssen war, daß sich die Vorstellung von politischer Belastung durch den Nationalsozialismus an der Spitze des Säuberungsapparates stärker gewandelt hatte als an seiner Basis. Da ein Teil des KRUA-Personals schon seit langem in diesen Gremien saß ${ }^{156}$ und es juristisch geschulte Kräfte - von einem Landkreis abgesehen - verstanden hatten, sich dieser undankbaren Aufgabe zu entziehen, hatten die Ausschüsse den rapiden Wandel der Kriterien kaum mitvollzogen. Für die Spruchkammern kamen deren Vorschläge aber aus einer anderen Welt. Der Vorwurf der Kammern an die Kreisuntersuchungsausschüsse, doch die Maßstäbe zu beachten, die inzwischen in Nordwürttemberg herrschten, war unsinnig, denn am Ort war ein Nazi eben trotzdem ein Nazi geblieben. Innerhalb der parteipolitisch und sozial heterogen zusammengesetzten Ausschüsse gab es darüber kaum Meinungsverschiedenheiten: „Die Ausschüsse, in denen Differenzen und Spannungen entstehen zwischen dem Vorsitzenden und dem einen oder anderen Parteivertreter, sind Gott sei Dank äußerst selten." (Traber) ${ }^{157}$. Offenbar bestand eine Art Konsens darüber, wer sich, von allen formalen Zugehörigkeiten zu Partei und Organisationen abgesehen, im Dritten Reich so weit mit dem Nationalsozialismus eingelassen hatte, daß er für einflußreiche Stellungen - und am Ort war der Kaufmann, der Lehrer oder der Dorfpolizist eben einflußreich - nicht mehr in Frage kam. Was Lutz Niethammer für die Spruchkammern der ersten Instanz in der US-Zone, die den KRUAS am ehesten vergleichbar waren, festgestellt hat, gilt auch in Württemberg-Hohenzollern: Sie hatten ,einen - relativ - energischen Säuberungswillen" ${ }^{158}$. Sie verstanden die Entnazifizierung am ehesten noch als politische Säuberung und nicht als ein Verfahren zur Ermittlung juristisch vorwerfbaren schuldhaften Handelns. Von den Normen, die sich inzwischen bei den Spruchkammern herausgebildet hatten, waren sie damit aber meilenweit entfernt. Daß es den Kreisuntersuchungsausschüssen an Virtuosität im Umgang mit dem Gesetzestext fehlte, war aufgrund ihrer Personalstruktur verständlich, in den Augen der Spruchkammermitglieder war es eine

154 Wie Anm. 151.

155 Schreiben des SK an die Spruchkammervorsitzenden v. 12.5. 1948; SIG, Wü 13/116.

156 Vergl. das Schreiben des SK an die Milreg v. 4. 11. 1947: „Die Kreisuntersuchungsausschüsse sind zum Teil mit den alten Vorsitzenden und Beisitzern, zum Teil mit neuen Mitgliedern besetzt." Nur im Kreis Hechingen hatte sich ein Jurist als Vorsitzender gefunden; SIG, Wü 13/ 456.

157 Arbeitstagung der Säuberungsorgane am 13. 4. 1948; SIG, Wü 13/32.

158 Niethammer, Entnazifizierung, S. 662. 
Katastrophe. Sie konnten mit dem Material der Ausschüsse nichts anfangen. Statt durch ihre „fortgesetzte negative Kritik“159 die Arbeit der Spruchkammern zu erschweren, sollten sich die KRUAS lieber ihrer eigentlichen Aufgabe, nämlich der Tatbestandsermittlung, widmen, gab der Vorsitzende einer Spruchkammer die Vorwürfe der Ausschüsse zurück. Die Spruchkammern könnten nicht umhin, ,ausdrücklich ein Versagen " 160 der Säuberungsgremien in den Kreisen festzustellen. Kurze Werturteile, wie sie von den Kreisausschüssen meist abgegeben würden, seien erstens nicht zu gebrauchen und zweitens seien die Vorschläge der Ausschüsse „durch die Entwicklung der Rechtsprechung überholt"161.

Wie in den Ländern der amerikanischen Zone, so war es auch in WürttembergHohenzollern zu einer völligen „Jurifizierung der Gesetzesauslegung“ gekommen ${ }^{162}$, die von dem Geist des Entnazifizierungsgesetzes nicht angekränkelt war. Die Spruchkammern dürften sich im politischen Säuberungsverfahren nicht von „ZWeckmäßigkeitsgründen" leiten lassen, so der Vertreter des Staatskommissars bei einer der Kammern in einer Denkschrift ${ }^{163}$, sondern müßten sich ganz auf die „Prüfung der persönlichen Verantwortlichkeit der Betroffenen“ konzentrieren. Denn, wenngleich im Text nicht ausdrücklich dargelegt, habe das Gesetz doch ,unzweifelhaft strafrechtlichen Charakter". Deshalb seien auch die allgemeinen Grundsätze des Strafrechts strikt anzuwenden. Entscheidend für die Urteilsfindung sei deshalb, ob „der Täter schuldhaft (vorsätzlich oder fahrlässig) " gehandelt habe. Da das Gesetz im wesentlichen auf die Unterstïtzung der NS-Gewaltherrschaft abstelle (ein damals gern gebrauchter kasuistischer Trick ${ }^{164}$ ) müsse die Beurteilung allein danach erfolgen, ob der Betroffene sich an ,an dem Zwang, der ausgeübt wurde, in vorwerfbarer Form beteiligt“ habe. Úberzeugte Nazi-Anhänger dagegen, die ,sogar eifrig tätig waren, aber in gutem Glauben und immer korrekt gehandelt" haben, könnten deshalb auch nicht in eine der beiden, einschneidende Sanktionen nach sich ziehenden Gruppen eingestuft werden. Der Leiter der Rechtsabteilung im Staatskommissariat für die politische Säuberung hieb in die gleiche Kerbe. Die Tendenz gehe dahin, „politische Verantwortlichkeit immer mehr unter dem Gesichtspunkt der Vorwerfbarkeit im rechtlichen Sinn zu sehen. Es scheint dies auch ein Erfordernis abendländischen Rechtsgefühls zu sein" ${ }^{165}$. Auch der Vorsitzende der Spruchkammer III, Amtsgerichtsrat Thaddäus Mayer aus Riedlingen, kurze Zeit später selbst Staatskommissar für die politische Säuberung ${ }^{166}$ (Traber war am 4.6. 1948 plötzlich gestorben ${ }^{167}$ ), meinte, ,nur wenn sich Betroffene sehr gehässig oder als Denunzianten oder sonstwie niedrig gesinnt benommen hät-

159 Schreiben des Vorsitzenden der Spruchkammer III an den SK v. 11. 3. 1948; SIG, Wü 13/152.

160 Besprechung Trabers mit den Spruchkammervorsitzenden am 21. 5. 1948; SIG, Wü 2, I, 610.

${ }^{161}$ Schreiben eines Spruchkammervorsitzenden an den SK v. 22. 5. 1948; SIG, Wü 15/2.

162 Niethammer, Entnazifizierung, S. 385.

163 Denkschrift für den SK v. 8. 4. 1948; SIG, Wü 13/25.

164 Vergl. Niethammer, Entnazifizierung, S. 643, Anm. 188.

165 Referat auf der Tagung der Säuberungsorgane am 13.4. 1948; SIG, Wü 13/26.

166 Beschluß in StaMiS 21.6.1948.

167 Traber starb an Herzschlag in seinem Dienstzimmer. Vergl. den Nachruf der Staatsregierung in SIG, Wü 13/230. 
ten", sei ein Urteil mit ernsten Konsequenzen für die berufliche Stellung angebracht $^{168}$. Gegenüber Traber bekräftigte er diese Auffassung noch einmal, indem er schrieb $^{169}$, die Beschränkung der Berufsausübung sei eine so harte Maßnahme, daß ,sie nur verhängt werden kann, wenn der Betroffene entweder gewalttätig oder gehässig war“. Wenn der Betroffene „geglaubt hat, einer guten und gerechten Sache zu dienen, wenn er sich im übrigen korrekt betragen hat, und wenn er sich vom Nationalsozialismus nach Möglichkeit zurückgezogen hat, nachdem er seinen Irrtum erkannt hatte" - hier erfolgte dann vor den Kammern regelmäßig die nicht selten mit einem Paket ,Persilscheinen' unterstützte sogenannte Würdigung der Gesamtpersönlichkeit - dann, so fuhr der zukünftige Säuberungskommissar fort, „kann er wegen seiner politischen Úberzeugung oder seinem politischen Irrtum nicht bestraft werden“. Ein Denkzettel, dann meist in Form eines Reichsmarkbetrages, wegen „Verletzung seiner sittlichen Pflichten" könne diesem dagegen aber durchaus verabreicht werden. Niemand, auch die Militärregierung nicht, könne gegen diese Rechtsauslegung etwas unternehmen. Die Spruchkammern seien unabhängig und nur dem Gesetz unterworfen, ihre Vorsitzenden Richter oder zum Richteramt befähigten Juristen, die nicht anders urteilten als ordentliche Gerichte auch. Es sei allein zu prüfen, ob „Tatbestandsmerkmale, an die das Gesetz bestimmte Rechtsfolgen knüpft, vorliegen. Sind solche Tatbestandsmerkmale nicht erwiesen, dann kann der Betroffene mit ihnen auch nicht belastet werden". Damit war vor den Kammern jeglicher politische Aspekt der Entnazifizierung begraben. Alle „Werturteile“ der Untersuchungsausschüsse, wie die juristisch geschulten Mitglieder der Spruchkammern die Ermittlungen der KRUAS abschätzig nannten, fielen bei diesem Verständnis der Säuberung glatt durch. Die Krone setzte der Vertreter des Staatskommissars bei der Spruchkammer I der „Verwendung juristischer Abstraktionen aus politischen Motiven " 170 auf: Es sei klar, daß jetzt die meisten Entscheide der Ära Künzel wieder aufgehoben werden müßten, wenn man bedenke, daß ,nur Laien, und zwar politische Gegner über die Mitglieder der NSDAP zu Gericht saßen“171! „Der Mut und die Wahrheit allein“ könne die Säuberung auf den richtigen Weg führen, hatte er schon früher gemeint, und „da die politische Säuberung in den Händen der CDU liegt, erwartet das Volk mit Recht, daß die Säuberung im Geiste der Nächstenliebe und der Versöhnung durchgeführt wird“172. Traber selbst fand noch eine griffigere Formel: Versittlichung der Säuberung ${ }^{173}$.

So sehr diese Auslegung aus dem Text des Gesetzes herauszulesen und rechtspositivistisch plausibel zu machen sein mochte, so weit blieben die führenden Juristen des Säuberungsapparates doch hinter den hoch gesteckten eigenen Ansprüchen zurück.

\footnotetext{
168 Sitzung Trabers mit den Spruchkammervorsitzenden am 21. 5. 1948; SIG, Wü 2, I, 610.

169 Schreiben v. 22. 5. 1948; SIG, Wü 15/2.

170 Niethammer, Entnazifizierung, S. 664.

171 Denkschrift für den SK v. 26. 4. 1948; SIG, Wü 13/25.

172 Wie Anm. 163.

173 Vergl. seine Begrüßungsansprache auf der Arbeitstagung mit den KRUA-Vorsitzenden in Tübingen am 13. 4. 1948; SIG, Wü 13/26.
} 
Sie selbst verletzten dabei selbstgesetzte strenge Ansprüche. Der Leiter der Rechtsabteilung im Staatskommissariat erklärte nämlich, es sei leitender Gedanke bei der Entnazifizierung ,im Hinblick auf eine erwartete Länder-Vereinigung auch auf diesem Gebiet eine möglichst umfassende Rechtseinheit vorzubereiten“174. Dazu wurde nun versucht, die Südwürttemberger nicht durch allzu harte Sanktionen bei der politischen Säuberung in eine beruflich ungünstige Ausgangslage geraten zu lassen. Traber, dem es ein „Bedürfnis“ war, der Militärregierung die Gründe für die „erheblich milder" gewordenen Säuberungsurteile zu erläutern ${ }^{175}$, versuchte der Besatzungsmacht dieses Phänomen so zu deuten: Die Künzel-Bescheide hätten zu einer „Abwanderung tüchtiger und tüchtigster Kräfte aus Südwürttemberg nach Nordwürttemberg geführt. Es ist also ein Gebot der Gerechtigkeit und der Rücksicht auf die wirtschaftliche Entwicklung unseres Landes, eine Angleichung unserer Rechtsprechung an die von Nordwürttemberg herbeizuführen.“ Diese ,erlittenen wirtschaftlichen Nachteile sind gerechterweise zu berücksichtigen und müssen auf die zu schöpfenden Sühnemaßnahmen sich auswirken". Abgesehen von dem Lapsus, daß er gegenüber der Militärregierung im Konflikt um die Eingriffsrechte bei Urteilen der InterniertenSpruchkammer gerade umgekehrt argumentiert hatte ${ }^{176}$, war dies das genaue Gegenteil des von ihm und den Spruchkammern immer wieder für sakrosankt erklärten Rechts der richterlich unabhängigen Entscheidung nach erwiesenen Tatbeständen. Dieser Verdrehung selbst postulierter Normen verstand er sogar höhere Weihen zu geben, die innerhalb des Gouvernement Militaire mit gemischten Gefühlen aufgenommen worden sein dürften. Wenn der französische Ministerpräsident Robert Schuman vor kurzem gesagt habe, daß „alles getan werden müsse, um die Völkerverständigung - wobei er sicher in erster Linie die Verständigung zwischen Frankreich und Deutschland im Auge gehabt hat - zu fördern, so glaube ich, daß die Spruchkammern mit ihrer veränderten Rechtsprechung ganz im Sinne dieser Bestrebungen arbeiten“.

Im gleichen Brief machte der Säuberungskommissar auch darauf aufmerksam, daß drei Jahre nach dem Zusammenbruch der zeitliche Abstand „die Dinge in einem ruhigeren Licht, in einer gereifteren Beurteilung erscheinen lassen und sie einer sachlicheren Behandlung zugeführt hat". Schon früher war auch den KRUAS entgegengehalten worden ${ }^{177}$, „daß für Entscheidungen, die durch Ressentiments beeinflußt sind, keine Berechtigung mehr besteht“. Die „Schärfe des Schwertes der Säuberungsorgane" habe überall abgenommen. Vorschläge, die noch den Geist der Jahre 1946/ 1947 atmeten, seien heute „für die Spruchkammern kaum mehr verwendbar“. Jetzt stand der neue Säuberungsapparat vor dem gleichen Dilemma, dessen rigorose Lösung Künzel seinerzeit zum Vorwurf gemacht worden war. Dieser hatte entgegen dem Stimmungswandel versucht, die Maßstäbe der Beurteilung nicht zu verändern, um früher ins Verfahren Gelangte nicht zu benachteiligen; das war weitgehend auch

174 Referat auf der Tagung am 13.4. 1948; ebd.

175 Schreiben des SK an Milreg v. 27. 4. 1948; SIG, Wü 2, III, P 1016/9.

176 Wie Anm. 109.

177 Wie Anm. 159. 
gelungen, weil in Reutlingen alle Entscheidungen zentral kontrolliert werden konnten. In den je einzelnen Verhandlungen vor den Spruchkammern, mit zunehmendem Abstand zum Nationalsozialismus und unter dem Eindruck des stärker werdenden Sogs des westlichen Integrationsprozesses und der Jurifizierung der Kriterien, wurden die Sanktionen für die Betroffenen nun aber zusehends milder. Ohne Frage eine $\mathrm{Zu}$ mutung für elementares Gerechtigkeitsempfinden, eine Ungerechtigkeit gegenüber tatsächlich nur nominell Belasteten und - nach der Massenamnestierung - ein Affront gegenüber den „Nichtbetroffenen“ oder gar „Entlasteten“. Der „,moralische Bankrott" der Entnazifizierung war tatsächlich offenbar geworden, wie Paul Binder (CDU), ehemaliger Landesdirektor der Finanzen von Württemberg-Hohenzollern, in einem Zeitungsartikel feststellte ${ }^{178}$; das Säuberungsverfahren war wirklich gescheitert, am wenigsten allerdings, wie er meinte, ,,an dem Mangel strafrechtlich geschulter Kräfte".

Die Befürchtungen derer, die in dem alten Verwaltungsverfahren ein prinzipiell vernünftiges, lediglich mit korrigierbaren Mängeln durchgeführtes Entnazifizierungsmodell gesehen hatten und vor seiner Ersetzung durch ein ,judiziäres“ Säuberungssystem gewarnt hatten, darunter auch Carlo Schmid, waren von der Praxis bestätigt worden. Der Mehraufwand an Zeit hätte einen vielfachen Personalaufwand erfordert, um die politische Säuberung in einem vernünftigen Zeitraum abzuschließen. Da sich niemand mehr zur Verfügung stellte, die Säuberungsorgane deshalb auch nicht vermehrt werden konnten, mußten schon allein deshalb - auch ohne die Jurifizierung der gesamten Entnazifizierung - die Urteile immer unangemessener ausfallen, ,immer mehr in einem den Belasteten günstigen Sinne verwischt" werden ${ }^{179}$. Nur durch Amnestien für die leichten Fälle konnte den Kammern Luft für eine Konzentrierung auf schwerer belastete Fälle geschaffen werden. Das hatte auch die französische Militärregierung eingesehen. Für eine solche Wende war es nun aber wegen der gewandelten Säuberungskriterien zu spät. Die faktisch blockierten Revisionsfälle mit einschneidenden Sanktionen ebenso wie die noch hinzukommenden Neufälle schwereren Kalibers kamen jetzt in den vollen Genuß des Niedergangs der politischen Säuberung. So war der Sonderkurs der Militärregierung in Württemberg-Hohenzollern nur vordergründig ein Erfolg, in Wirklichkeit aber ein Pyrrhussieg gewesen. Denn im Strudel der Weißwäsche, der nach dem Bersten des Dammes losbrach, mit dem das Gouvernement Militaire in Tübingen ein Jahr lang die Rehabilitierungswelle zu bremsen versucht hatte, verschwanden jetzt so gut wie alle wirklich schwer Belasteten. Bald waren sie „Mitläufer“, amnestiert, integriert und entnazifiziert, was jetzt soviel bedeutete wie: „Mit frischer weißer Weste in die Gesellschaft zurückgeschickt ${ }^{\text {"180 }}$.

178 Vergl. den Artikel „Ende der politischen Säuberung“ in der „Schwäbischen Zeitung“ v. 13. 4. 1948.

179 Schreiben eines Hechinger Richters an den SK v. 8. 3. 1948; SIG, Wü 13/32.

${ }^{180}$ Niethammer, Entnazifizierung, S. 13. 